\title{
STARD4 promotes breast cancer cell malignancy
}

\author{
MIN ZHANG ${ }^{1 *}$, ZHEN XIANG $^{1 *}$, FENG WANG ${ }^{1}$, RONG SHAN $^{1}$, LING $^{2}{ }^{2}$, JUAN CHEN $^{3}$, \\ BAO-AN LIU ${ }^{4}$, JUAN HUANG ${ }^{5}$, LUN-QUAN SUN ${ }^{2}$ and WEI-BING ZHOU ${ }^{1}$ \\ ${ }^{1}$ Department of Oncology, ${ }^{2}$ Center for Molecular Medicine, Departments of ${ }^{3}$ Pharmacy and ${ }^{4}$ Pathology, \\ ${ }^{5}$ Hunan Province Clinic Meditech Research Center for Breast Cancer, Xiangya Hospital, \\ Central South University, Changsha, Hunan 410008, P.R. China
}

Received January 20, 2020; Accepted August 24, 2020

DOI: $10.3892 /$ or.2020.7802

\begin{abstract}
Breast cancer (BRCA) is one of the most common malignancies encountered in women worldwide. Lipid metabolism has been found to be involved in cancer progression. Steroidogenic acute regulatory protein-related lipid transfer 4 (STARD4) is an important cholesterol transporter involved in the regulatory mechanism of intracellular cholesterol homeostasis. However, to the best of our knowledge, the molecular functions of STARD4 in BRCA are unclear. Immunohistochemical staining and public dataset analysis were performed to investigate the expression levels of STARD4 in BRCA. In the present study, high expression of STARD4 was identified in BRCA samples and higher STARD4 expression was significantly associated with shorter distant metastasis-free survival time in patients with BRCA, which indicated that STARD4 may be associated with BRCA progression. Cell cytometry system Celigo ${ }^{\circledR}$ analysis, Cell Counting K-8 assays, flow cytometry, wound healing assays and transwell assays were used to investigate the effects of STARD4 knockdown on proliferation, cell cycle, apoptosis and migration in BRCA cells. Loss-of-function assays demonstrated that STARD4 acted as an oncogene to promote proliferation and cell cycle progression, while suppressing apoptosis in BRCA cells in vitro and in vivo. Furthermore, knockdown of STARD4 significantly suppressed BRCA metastasis. To assess the mechanism of action of STARD4, microarray analysis was performed following STARD4 knockdown in MDA-MB-231 cells. The data were analyzed in detail using bioinformatics, and a series of genes, including E74 like ETS transcription factor 1, cAMP responsive element binding protein 1 and $\mathrm{p} 21$ (RAC1) activated kinase 2, which
\end{abstract}

Correspondence to: Professor Wei-Bing Zhou, Department of Oncology, Xiangya Hospital, Central South University, 87 Xiangya Road, Changsha, Hunan 410008, P.R. China

E-mail: zhouweibing298@csu.edu.cn

*Contributed equally

Key words: breast cancer, steroidogenic acute regulatory protein-related lipid transfer, proliferation, migration, biomarker have been previously reported to be crucial genes implicated in the malignant phenotype of cancer cells, were identified to be regulated by STARD4. Loss-of function assays demonstrated that knockdown of STARD4 suppressed BRCA proliferation and migration. These findings suggested that STARD4 had an oncogenic effect in human BRCA progression.

\section{Introduction}

Breast cancer (BRCA) is the most common type of malignancy in females worldwide $(1,2)$. Over the past decades, patients with BRCA have been usually treated with radiotherapy, chemotherapy or their combination according to the tumor type, histological stage, tumor size, lymph node metastasis and metastatic site (3). However, the prognosis of patients with BRCA remains poor (4). Furthermore, the incidence of BRCA is increasing (5). In 2018, 2.1 million newly diagnosed cases of BRCA were reported worldwide, accounting for almost a quarter of the total number of diagnosed cancers in female subjects (5). Therefore, understanding the molecular mechanisms underlying BRCA progression can be used to identify novel biomarkers for the early detection of this disease.

An increasing number of studies have demonstrated that the abnormal regulation of metabolism-associated pathways is associated with tumorigenesis and the development of human cancer (6-9). Lipid metabolism disorders have been reported to be associated with a variety of diseases, such as cancer (10). Lipid metabolism is involved in regulating multiple cellular biological activities in cancer cells, such as cell proliferation and apoptosis. The steroidogenic acute regulatory protein-related lipid transfer (STARD) domain family serves a crucial role in the transportation of cholesterol $(11,12)$. STARD family proteins serve a role in non-vesicular lipid transport and cell signaling via their interaction with cholesterol, phospholipids, sphingolipids and bile acids (13). The STARD4 protein was initially identified by Soccio et al (14) in 2002. STARD4 is located in both the nuclear and cytoplasmic regions (15). STARD4 is involved in the regulatory mechanism of intracellular cholesterol homeostasis (16). Silencing of STARD4 results in elevated levels of intracellular free cholesterol (17). Furthermore, overexpression of STARD4 promotes the formation of cholesterol esters, suggesting that STARD4 can facilitate the transport of cholesterol to the endoplasmic reticulum and mitochondria (18). A previous study has indicated 
that knockdown of STARD4 in the liver cancer HepG2 cell line disrupts cholesterol trafficking, suggesting that STARD4 may be associated with cancer progression (19). However, the roles of STARD4 in the development of BRCA require further investigation.

The present study initially investigated the role of STARD4 in BRCA and elucidated the effects of STARD4 on the proliferation of BRCA cells. The data provide important information for understanding BRCA pathogenesis.

\section{Materials and methods}

Tissue samples. A total of 121 BRCA samples and 49 matched normal tissues were collected from the Department of Breast Surgery, Xiangya Hospital, Central South University (Changsha, China). Patients with BRCA were aged 31-76 years, with a median age of 63 years. The samples were collected from female patients with BRCA who were diagnosed according to the postoperative pathological report between January 2016 and December 2018 after surgical resection. Cases of invasive ductal carcinoma, intraductal carcinoma and mucinous adenocarcinoma were included in the present study. Cases with multiple primary cancers and a postoperative positive margin were excluded. The postoperative immunohistochemical (IHC) staining results of the patients for the markers estrogen receptor (ER), progesterone receptor (PR), HER2 and Ki67 were recorded in detail. Clinical and pathological data, including age, histopathological grade, number of axillary lymph node dissection, and metastasis and site of metastasis, were collected (Table I). The patients were all female and the median age was 63 years. The present study was approved by the Ethics Committee of Xiangya Hospital (Changsha, China). Written informed consent was obtained from all patients.

The present study first evaluated the expression levels of STARD4 in 57 BRCA cell lines by analyzing data in the Cancer Cell Line Encyclopedia (CCLE) database (https://portals. broadinstitute.org/ccle) $(20,21)$. The expression levels of STARD4 in T1, T2, T3 and T4 stage BRCA samples were analyzed using the Betastasis database (http://www.betastasis. com). The expression levels of STARD4 in different types of BRCA were analyzed using the Tumor Immune Estimation Resource (TIMER) database (https://cistrome.shinyapps. io/timer/), which is based on The Cancer Genome Atlas RNA-sequence data (https://portal.gdc.cancer.gov/). TIMER provides six major analytic modules that allow users to interactively explore the associations between immune infiltrates and a wide spectrum of factors, including gene expression, clinical outcomes, somatic mutations and somatic copy number alterations (22). The prognostic value of STARD4 was evaluated using Kaplan-Meier Plotter (www.kmplot.com). To analyze the association between STARD4 levels and distant metastasis-free survival (DMFS) time, patient samples were divided into two groups (low and high expression) based on median mRNA levels with a hazard ratio with $95 \%$ confidence intervals and log-rank P-values (23). Log-rank P-values $<0.05$ were considered statistically significant.

IHC staining and evaluation. Tissue samples were fixed in $10 \%$ $(\mathrm{v} / \mathrm{v})$ formaldehyde at room temperature for $24 \mathrm{~h}$, embedded in paraffin and cut into $5-\mu \mathrm{m}$ sections. All IHC staining assays used in the present study were conducted as previously described (24). The biotin-labeled IgG (cat. no. Sp-9001; 1:1,000; OriGene Technologies, Inc.) was used as secondary antibody for $30 \mathrm{~min}$ at room temperature. Dehydration was subsequently performed and sample sections were sealed using cover glasses. Five fields were randomly selected and imaged under an optical microscope (BX51T-PHD-J11; Olympus Corporation). The images were analyzed using Image-Pro Plus 6.0 (Media Cybernetics, Inc.). The staining was assessed independently by two pathologists in a blinded manner and all discrepancies were resolved by consensus.

STARD4 immunohistochemical staining was performed using a polyclonal antibody against STARD4 (dilution, 1:200; cat. no. ab202060; Abcam). The staining intensity was divided into the following categories: 0 points, negative (-); 1-2 points, weakly positive $(+)$; 3-4 points, positive $(++)$; 6-9 points, strongly positive (+++). The percentage of positively-stained cells was scored as follows: $0,0-5 \% ; 1,5-25 \% ; 2,25-50 \%$; $3,50-100 \%$.

ER and PR immunohistochemical staining was performed using a mouse monoclonal anti-human ER antibody (clone, 1D5; Dako; Agilent Technologies, Inc.) and a mouse monoclonal anti-human PR antibody (clone, 636; Dako; Agilent Technologies, Inc.) at a dilution of 1:100. The cut-off value for a positive result was positive staining for ER and $\mathrm{PR}$ in $\geq 1 \%$ of tumor cells in 10 selected tumor sub-regions (25). The results were recorded as the percentage of positively-stained nuclei, and the intensity was graded between 0 and $3+$ as follows: 0 (negative result), positive staining in $<1 \%$ of the tumor cells; $1+$, mildly distinct, positive staining in $\leq 25 \%$ of the tumor cells; $2+$, moderately distinct, positive staining in $25-50 \%$ of the tumor cells; and $3+$, strong, positive staining in $>50 \%$ of the tumor cells.

HER2 immunohistochemical staining was performed using the HercepTest ${ }^{\mathrm{TM}}$ assay (Dako; Agilent Technologies, Inc.) according to manufacturer's protocols. The expression levels of HER2 were initially determined by immunohistochemistry and graded between 0 and 3+ as follows: 0 (negative result), absence or presence of HER 2 in $<10 \%$ of the tumor cells; $1+$ (negative result), membranous, weak and discontinuous staining in $>10 \%$ of the tumor cells; $2+$ (questionable result), membranous, low/moderate and continuous staining in $>10 \%$ of the tumor cells, or membranous, intense and continuous staining in $\leq 30 \%$ of the tumor cells; and $3+$ (positive result), membranous, intense and continuous staining in $>30 \%$ of the tumor cells. Samples with HER2 scores of 2+ were confirmed to be HER2-negative or HER2-positive using fluorescence in situ hybridization analysis as previously described (26).

Ki67 immunohistochemical staining was performed using a mouse monoclonal anti-human Ki67 antibody (dilution, 1:100; clone, MIB-1; Dako; Agilent Technologies, Inc.). At least three fields in particular staining 'hot-spots' were selected in order to represent the spectrum of staining observed upon the initial overview of the entire section. The cancer cells in the three micrographs were manually counted (500-1,000 cells were counted), and the percentage of positively-stained cancer cells was considered to be the Ki67 score (27).

Cell culture, and apoptosis, proliferation and migration assays. HCC1937 and MDA-MB-231 cells were obtained 
Table I. Clinicopathological characteristics of patients and STARD4 expression in breast cancer.

\begin{tabular}{|c|c|}
\hline Characteristics & Number of cases $(\%$ \\
\hline \multicolumn{2}{|l|}{ Age, years } \\
\hline$£ 40$ & $21(17.4)$ \\
\hline$>40$ & $100(82.6)$ \\
\hline \multicolumn{2}{|l|}{ T stage } \\
\hline $\mathrm{T} 1-\mathrm{T} 2$ & $101(83.5)$ \\
\hline T3-T4 & $20(16.5)$ \\
\hline \multicolumn{2}{|l|}{ M stage } \\
\hline M0 & $117(96.7)$ \\
\hline M1 & $4(3.3)$ \\
\hline \multicolumn{2}{|l|}{$\mathrm{N}$ stage } \\
\hline No & $55(45.5)$ \\
\hline N1-N3 & $66(54.5)$ \\
\hline \multicolumn{2}{|l|}{ TNM stage } \\
\hline I-II & $82(67.8)$ \\
\hline III-IV & $39(32.2)$ \\
\hline \multicolumn{2}{|l|}{ Histological stage } \\
\hline Intraductal carcinoma & $10(8.3)$ \\
\hline $\mathrm{I}$ & $5(4.1)$ \\
\hline II & $78(64.5)$ \\
\hline III & $27(22.3)$ \\
\hline Mucinous adenocarcinoma & $1(0.8)$ \\
\hline \multicolumn{2}{|l|}{ Metastasis } \\
\hline No & $68(56.2)$ \\
\hline Yes & $53(43.8)$ \\
\hline \multicolumn{2}{|l|}{ Lymph node metastasis, \% } \\
\hline$<20$ & $84(69.4)$ \\
\hline$\geq 20$ & $37(30.6)$ \\
\hline \multicolumn{2}{|l|}{ Molecular type } \\
\hline Luminal & $69(57.0)$ \\
\hline HER2+ & $43(35.5)$ \\
\hline TNBC & $9(7.4)$ \\
\hline \multicolumn{2}{|l|}{ ER } \\
\hline Negative & $37(30.6)$ \\
\hline Positive & $84(69.4)$ \\
\hline \multicolumn{2}{|l|}{ PR } \\
\hline Negative & $51(42.1)$ \\
\hline Positive & $70(57.9)$ \\
\hline \multicolumn{2}{|l|}{ HER } \\
\hline Negative & $78(64.5)$ \\
\hline Positive & $43(35.5)$ \\
\hline \multicolumn{2}{|l|}{ STARD4 expression } \\
\hline Low & $59(48.8)$ \\
\hline High & $62(51.2)$ \\
\hline
\end{tabular}

ER, estrogen receptor; PR, progesterone receptor; STARD4, steroidogenic acute regulatory protein-related lipid transfer 4; TNBC, triple-negative breast cancer.

from The Cell Bank of Type Culture Collection of the Chinese Academy of Sciences and cultured in low-glucose DMEM
(Gibco; Thermo Fisher Scientific, Inc) with 10\% FBS (Gibco; Thermo Fisher Scientific, Inc.) and $1 \%$ penicillin-streptomycin (Gibco; Thermo Fisher Scientific, Inc.) in a $37^{\circ} \mathrm{C}$ incubator with $5 \% \mathrm{CO}_{2}$. Briefly, recombinant lentiviral vectors were obtained Shanghai Genechem Co., Ltd. A total of $6 \mu \mathrm{g}$ shRNA plasmids and shRNA control were transfected to knockdown target expression levels using Lipofectamine 3000 reagent (Invitrogen; Thermo Fisher Scientific, Inc.), according to standard molecular techniques. At $48 \mathrm{~h}$ after transfection, the transfection efficiency was determined using reverse transcription-quantitative (RT-q)PCR and western blotting. The short hairpin RNA (sh)STARD4 sequence was 5'-CCGGTCCTA TACTGTGGGCTATAAACTCGAGTTTATAGCCCACAG TATAGGATTTTTG-3'. The sh-cAMP responsive element binding protein 1 (CREB1) sequence was 5'-CCGGTCCCA ACAAATGACAGTTCAACTCGAGTTGAACTGTCATTT GTTGGGATTTTTG-3'. The shcontrol sequence was 5'-CCG GTCTTCTCCGAACGTGTCACGTCTCGAGACGTGACA CGTTCGGAGAAGATTTTTG-3'. Lentivirus construction and infection were performed as previously described (28).

For the cell proliferation assay, 2,000 HCC1937 or MDA-MB-231 cells/well were seeded into 96-well plates. The optical density was detected at $450 \mathrm{~nm}$ using a microplate reader after adding $10 \mu \mathrm{l}$ Cell Counting Kit-8 (CCK-8; Dojindo Molecular Technologies, Inc.) reagent to each well at each time point (day 1, 2, 3, 4 and 5) according to the manufacturer's protocol.

The cell counting assay was performed using the Celigo image cytometer (Nexcelom Bioscience LLC). For cell cytometry system Celigo ${ }^{\circledR}$ analysis, HCC1937 and MDA-MB-231 cells transfected with shSTARD4 or negative control were seeded into 96 -well plates (1,500 cells/well) and cultured for 5 days. The cell images were captured and analyzed using the using a fluorescence microscope system (Celigo ${ }^{\circledR}$; Nexcelom Bioscience LLC). Each experiment was performed three times.

The apoptosis of HCC1937 and MDA-MB-231 cells was analyzed using a FACS Calibur flow cytometer (BD Biosciences) with a FITC Annexin V Apoptosis Detection kit (BD Biosciences. Cell apoptosis data were analyzed using FCS Express software (version 3.0; De Novo Software). Each experiment was performed three times.

The cell migration assay was performed as previously described using a Transwell assay (29). For the wound healing assay, HCC1937 and MDA-MB-231 cells were seeded into 6 -well plates in duplicate. Once the confluency of the cells reached $\sim 80 \%$, the monolayer of cells was wounded using a $10-\mu 1$ plastic pipette tip and then the scratched cells were rinsed with PBS and cultured with serum-free DMEM for $24 \mathrm{~h}$. The wound was imaged at 0,12 and $24 \mathrm{~h}$ using a fluorescence microscope (CK40-F200; Olympus Corporation) and then analyzed using ImageJ software (version 1.62; National Institutes of Health). The following formula was used: Wound closure rate $(\%)=$ migrated cell surface area/total surface area x100. Each experiment was performed three times.

$R T$ - $q P C R$. Total RNA was extracted from BRCA cell lines using the TRIzol reagent (Thermo Fisher Scientific, Inc.) and was transcribed to cDNA using the RevertAid First Strand cDNA Synthesis kit (Thermo Fisher Scientific, Inc.). Reverse transcription was conducted at $37^{\circ} \mathrm{C}$ for $1 \mathrm{~h}$, followed by $85^{\circ} \mathrm{C}$ 
for $5 \mathrm{sec}$ according to the manufacturer's protocol. RT-qPCR was performed using the QuantiTect SYBR-Green PCR kit (Roche Diagnostics) as previously described (30). The primer sequences are listed in Table SI. The $2^{-\Delta \Delta \mathrm{Cq}}$ method was used to calculate the relative expression levels of the target genes (31). GAPDH was used for normalization. The reaction conditions were as follows: $95^{\circ} \mathrm{C}$ for $10 \mathrm{~min}$, followed by $95^{\circ} \mathrm{C}$ for $30 \mathrm{sec}$, $60^{\circ} \mathrm{C}$ for $30 \mathrm{sec}$ and $72^{\circ} \mathrm{C}$ for $30 \mathrm{sec}(39 \mathrm{cycles})$, and finally $72^{\circ} \mathrm{C}$ for $10 \mathrm{~min}$.

In vivo tumor assays. A total of $3 \times 10^{6}$ STARD4-knockdown or control HCC1937 cells were suspended in PBS and injected subcutaneously into the dorsal skin of 6-week-old female BALB/c nude mice (10 mice/group) with a median weight of $20 \mathrm{~g}$ (Shanghai SLAC Laboratory Animal Co., Ltd.). The protocol for the animal experiments was approved by the Shanghai Medical Experimental Animal Care Commission (approval no. ShCI-14-008). Mice were housed under specific pathogen-free conditions at $25^{\circ} \mathrm{C}$ with a 12 -h light/dark cycle, and free access to food and water. The maintenance conditions for the mice were as follows: Humidity, 40-60\%; ventilation, 15 times/h. STARD4 knockdown and control luciferase-expressing HCC1937 cells were injected into the mice and monitored using an in vivo Imaging System (IVIS; PerkinElmer, Inc.). The animals were sacrificed when the tumors reached $1 \mathrm{~cm}$ in diameter. The mice were sacrificed 7 weeks after injection using $\mathrm{CO}_{2}$ (with a flow rate of $\mathrm{CO}_{2}$ for euthanasia displacing $\leq 30 \%$ of the chamber volume/min). The volume and weight of all nude mice were measured after 4 weeks. Tumor growth was calculated using the following formula: Volume $=0.5 \mathrm{x}$ length $\mathrm{x}$ width ${ }^{2}$.

Western blotting. Total protein was extracted from cells with RIPA buffer (Beyotime Institute of Biotechnology). The BCA assay kit (Boster Biological Technology) was used to measure the total protein concentration. Protein $(30 \mu \mathrm{g} / \mathrm{lane})$ was subsequently separated by $12 \%$ SDS-PAGE, followed by transfer to PVDF membranes. Subsequently, the membranes were blocked with 3\% BSA (Sangon Biotech Co., Ltd.)/TBS with $0.05 \%$ Tween-20 (TBST; Sangon Biotech Co., Ltd.) for $2 \mathrm{~h}$ at room temperature and incubated with primary antibodies at $4^{\circ} \mathrm{C}$ overnight. The PVDF membranes were rinsed three times for $5 \mathrm{~min}$ each with TBST and incubated with HRP-conjugated secondary antibodies for $1 \mathrm{~h}$ at room temperature. The antibodies are listed in Table SII. The total protein levels were assessed using enhanced chemiluminescence reagents (Thermo Fisher Scientific, Inc.). ImageJ 6.0 software (National Institutes of Health) was used to analyze the images.

Microarray and expression analyses. Total RNA was extracted using TRIzol reagent (Invitrogen; Thermo Fisher Scientific, Inc.) and quantified by the NanoDrop ND-2000 (Thermo Fisher Scientific, Inc.). The RNA integrity was assessed using the Agilent Bioanalyzer 2100 (Agilent Technologies, Inc). Whole-genome gene expression levels were examined using the Gene Chip Prime View Human Gene Expression Array (Thermo Fisher Scientific, Inc.). Sample labeling, microarray hybridization, washing and gene normalization were performed according to the manufacturer's protocols. RNA integrity was also examined using an Agilent Bioanalyzer 2100 (cat. no. G2938A; Agilent Technologies, Inc.). To obtain biotin-tagged cDNA, total RNA was subsequently amplified, labeled and purified using a WT PLUS Reagent kit (cat. no. 902280; Affymetrix; Thermo Fisher Scientific, Inc.). Array hybridization was performed using an Affymetrix GeneChip Human Gene 2.0 ST Array (Affymetrix; Thermo Fisher Scientific, Inc.) and Hybridization Oven 645 (cat. no. 00-0331-220V; Affymetrix; Thermo Fisher Scientific, Inc.). The Gene Chip was subsequently washed using a Hybridization, Wash and Stain kit (cat. no. 900720; Affymetrix; Thermo Fisher Scientific, Inc.) in a Fluidics Station 450 (cat. no. 00-0079, Affymetrix; Thermo Fisher Scientific, Inc.). A GeneChip Scanner 3000 (cat. no. 00-00213; Affymetrix; Thermo Fisher Scientific, Inc.) was used to scan the results, which were analyzed by Command Console Software 4.0 (Affymetrix; Thermo Fisher Scientific, Inc.) to summarize probe cell intensity data, namely, the CEL files with default settings. Following this, CEL files were normalized according to gene and exon levels using Expression Console Software 4.0 (Affymetrix; Thermo Fisher Scientific, Inc.). All procedures, including array hybridization and scanning, were independently performed according to a standard protocol (32) for microarray experiments $(n=3)$.

Differentially expressed mRNAs were subsequently identified using fold change values. The threshold for upregulated and downregulated genes was $\geq 1.5$. Genes that were differentially expressed were identified based on the following criteria: $\mathrm{P}<0.05$ and absolute fold change $>1.5$.

Statistical analysis. All statistical analyses were performed using GraphPad Prism 6.0 (GraphPad Software, Inc.). All data are presented as the mean \pm SEM. All assays were conducted at least three times. The unpaired Student's t-test, Mann-Whitney U test and Wilcoxon matched-pairs signed rank test were used to analyze the differences between two groups according to the test condition. One-way ANOVA with Tukey's post hoc test was used to analyze the differences among multiple groups. Survival curves were estimated using the Kaplan-Meier method and the log-rank test. $\mathrm{P}<0.05$ was considered to indicate a statistically significant difference.

\section{Results}

STARD4 is upregulated in breast carcinoma. In order to evaluate the expression levels of STARD4 in BRCA, 121 BRCA samples and 49 adjacent normal tissue samples were collected from patients who underwent surgical resection. The clinicopathological characteristics and the expression levels of STARD4 in BRCA are shown in Table I. STARD4 was expressed in the nuclear regions in both BRCA and normal breast tissues (Fig. 1A-D). The comparison of the STARD4 levels between BRCA and normal samples demonstrated that STARD4 protein levels were significantly upregulated in 121 BRCA samples compared with in 49 adjacent normal tissues (Fig. 1E). The BRCA levels were upregulated in 49 paired BRCA samples (Fig. 1F).

The associations between STARD4 protein expression and the clinicopathological features of patients with BRCA 

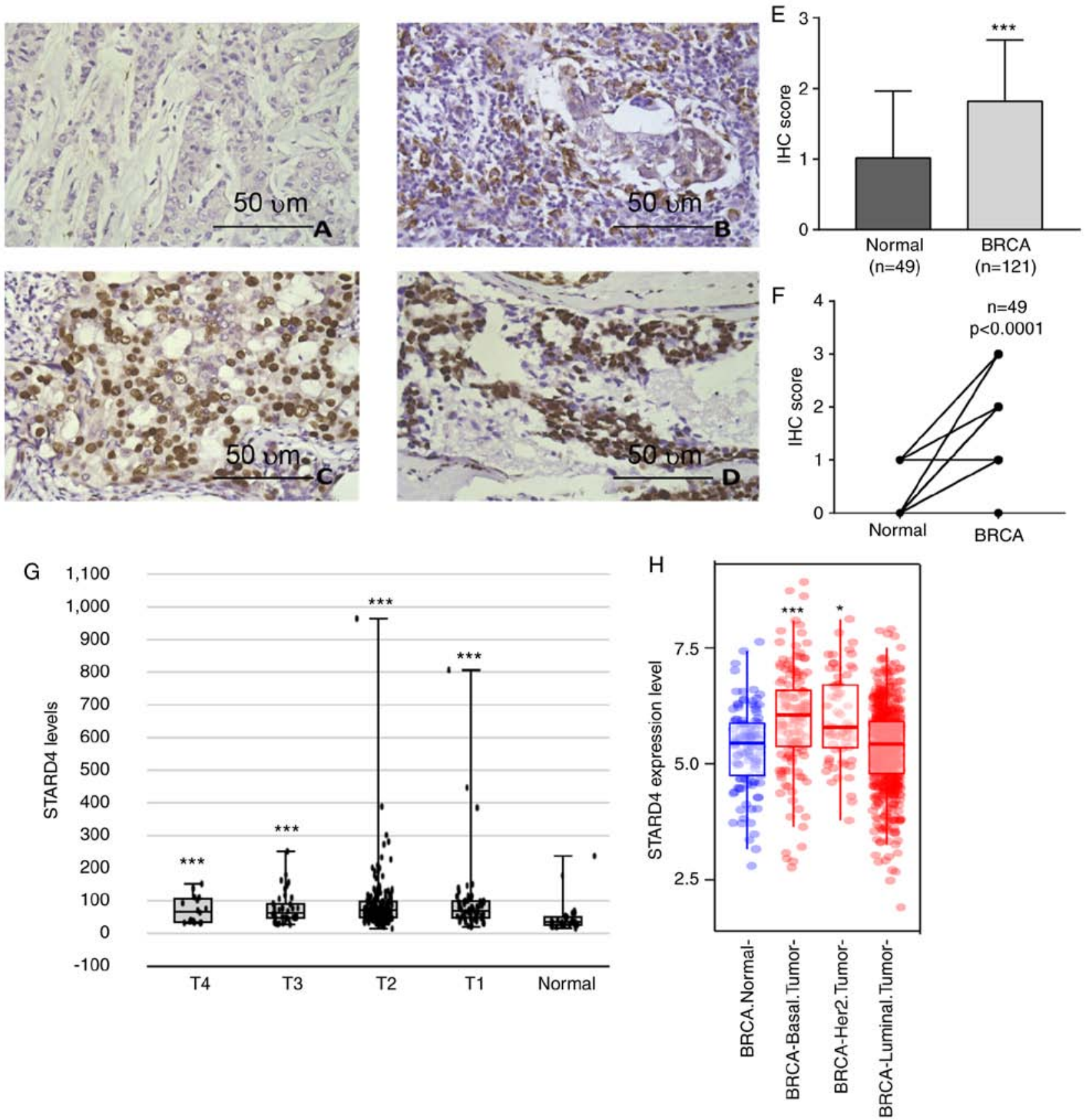

Figure 1. STARD4 expression is upregulated in BRCA samples. STARD4 expression was (A) negative, (B) weakly positive, (C) positive and (D) strongly positive in clinical BRCA samples as detected by IHC. Scale bar, $50 \mu \mathrm{m}$. (E) STARD4 protein levels were significantly upregulated in 121 BRCA samples compared with 49 adjacent normal tissue, and (F) upregulated in 49 paired BRCA samples. (G) STARD4 was upregulated in stage T1, T2, T3 and T4 BRCA samples compared with normal breast samples. (H) STARD4 expression was upregulated in basal and Her2-positive, but not in luminal BRCA samples compared with in normal breast tissues. For (E) statistical comparisons between groups of normalized data were performed using Mann-Whitney U test according to the test condition. For $(F)$ statistical comparisons between groups of normalized data were performed using the Wilcoxon matched-pairs signed rank test according to the test condition. ${ }^{*} \mathrm{P}<0.05,{ }^{* * *} \mathrm{P}<0.001$ vs. normal group. BRCA, breast cancer; IHC, immunohistochemistry; STARD4, steroidogenic acute regulatory protein-related lipid transfer 4.

are summarized in Table II. Positive protein expression of STARD4 was associated with advanced histological stage, metastatic status and ER expression. However, it was not observed to be significantly associated with age, $\mathrm{T}$ stage, $\mathrm{M}$ stage, $\mathrm{N}$ stage, PR and HER-2 expression. These results demonstrated that STARD4 was significantly associated with ER expression, but not PR expression. When analyzing the association between ER and STARD4 using the TIMER database, a negative correlation was observed between the two genes in all types of BRCA (Fig. S1 A), HER2-positive
BRCA (Fig. S1B) and luminal BRCA (Fig. S1C). However, STARD4 expression was positively correlated with ER expression in basal BRCA (Fig. S1D).

Furthermore, online public datasets were analyzed. When analyzing the Betastasis database, the data indicated that STARD4 expression was upregulated in T1, T2, T3 and T4 stage BRCA samples compared with in normal breast samples (Fig. 1G). However, STARD4 expression was not significantly different among the different stages. Furthermore, the TCGA dataset was analyzed to detect STARD4 levels in 
Table II. Association between STARD4 expression and clinicopathologic characteristics of patients with breast cancer.

\begin{tabular}{llll}
\hline & \multicolumn{2}{c}{ STARD4 } & \\
\cline { 2 - 2 } Characteristics & Low, n High, $\mathrm{n}$ & $\chi^{2}$ & P-value \\
\hline
\end{tabular}

$$
\begin{aligned}
& \text { Age, years } \\
& \leq 40 \\
& >40
\end{aligned}
$$

T stage

$\mathrm{T} 1-\mathrm{T} 2$

T3-T4

M stage

M0

M1

$\mathrm{N}$ stage

N0

$\mathrm{N} 1-\mathrm{N} 3$

TNM stage

I-II

III-IV

Histological stage

Intraductal carcinoma

I

II

III

Mucinous adenocarcinoma

$\begin{array}{llll}11 & 10 & 0.133 & 0.812 \\ 48 & 52 & & \end{array}$

Metastasis

No

Yes

Lymph node metastasis, \%

$\begin{array}{lrrrr}<20 & 44 & 40 & 1.441 & 0.244 \\ \geq 20 & 15 & 22 & & \\ \text { Molecular type } & & & & \\ \quad \text { Luminal } & 32 & 37 & 1.87 & 0.395 \\ \text { HER2 }^{+} & 24 & 19 & & \\ \text { TNBC } & 3 & 6 & & \\ \text { ER } & & & & \\ \text { Negative } & 11 & 26 & 7.726 & 0.006 \\ \text { Positive } & 48 & 36 & & \end{array}$

PR

$\begin{array}{lllll}\text { Negative } & 25 & 26 & 0.002 & >0.999 \\ \text { Positive } & 34 & 36 & & \\ \text { HER } & & & & \\ \text { Negative } & 36 & 42 & 0.597 & 0.454 \\ \text { Positive } & 23 & 20 & & \end{array}$

ER, estrogen receptor; PR, progesterone receptor; STARD4, steroidogenic acute regulatory protein-related lipid transfer 4; TNBC, triple-negative breast cancer.

different types of BRCA. STARD4 expression was upregulated in basal and Her2-positive BRCA tissues, whereas it was not upregulated in luminal BRCA samples compared with in normal breast tissues (Fig. 1H). The analysis demonstrated that STARD4 expression may be associated with BRCA progression and may serve as an early diagnostic biomarker. However, the dysregulation of STARD4 could not be used for the prediction of BRCA stage.

Upregulation of STARD4 expression is associated with poor BRCA prognosis. The association between STARD4 levels and DMFS time was determined using the Kaplan-Meier survival Plotter database. The median expression of STARD4 in all BRCA cases was selected as a cut-off to divide the BRCA samples into STARD4-high and -low groups. Kaplan-Meier survival curve analysis indicated that higher expression levels of STARD4 were significantly associated with shorter DMFS time in patients with BRCA (Fig. 2A).

Furthermore, the association between STARD4 expression and DMFS time was examined in patients with BRCA according to their clinicopathological characteristics, including ER, PR and HER2 status. The results indicated that high STARD4 expression was associated with poor DMFS rates compared with low STARD4 expression in patients with ER-negative (Fig. 2B), PR-negative (Fig. 2C) and HER2-positive (Fig. 2D) BRCA. However, dysregulation of STARD4 was not significantly associated with DMFS time in patients with ER-positive (Fig. 2E), PR-positive (Fig. 2F) and HER2-negative (Fig. 2G) BRCA. Furthermore, the present study evaluated the prognostic utility of STARD4 based on subtype (luminal and HER2). As presented in Fig. S2, although a potential tendency that higher expression levels of STARD4 were associated with shorter DMFS time in luminal A, luminal B and HER2-positive BRCA was observed, no significant association between STARD4 expression and DMFS time was observed in groups of patients based on subtype (luminal and HER2).

Knockdown of STARD4 suppresses cell proliferation in $B R C A$. Upregulation of STARD4 in BRCA suggested that STARD4 may serve as an oncogene in BRCA. Therefore, loss-of-functions assays were used to detect the effects of STARD4 on cell proliferation. The present study first evaluated the expression levels of STARD4 in 57 BRCA cell lines by analyzing the CCLE database $(20,21)$. The results demonstrated that STARD4 was highly expressed in multiple BRCA cell lines, including MDA-MB-231 and HCC1937 cells, which do not have the highest STARD4 levels; however, they are widely used in triple-negative BRCA research (Fig. 3A). Following transfection of HCC1937 (Fig. 3B and C) and MDA-MB-231 (Fig. 3D and E) cells with shSTARD4 lentivirus, the mRNA and protein levels of STARD4 in BRCA cells were reduced compared with those of the control group.

Subsequently, the effects of STARD4 on BRCA proliferation were assessed using a Celigo cell counting assay for 5 days. Knockdown of STARD4 reduced cell proliferation in HCC1937 (Fig. 3F) and MDA-MB-231 (Fig. 3H) cells compared with in control cells. In addition, a CCK-8 assay revealed that knockdown of STARD4 suppressed the HCC1937 (Fig. 3G) and MDA-MB-231 (Fig. 3I) cell proliferation rate at day 3,4 and 5 . 

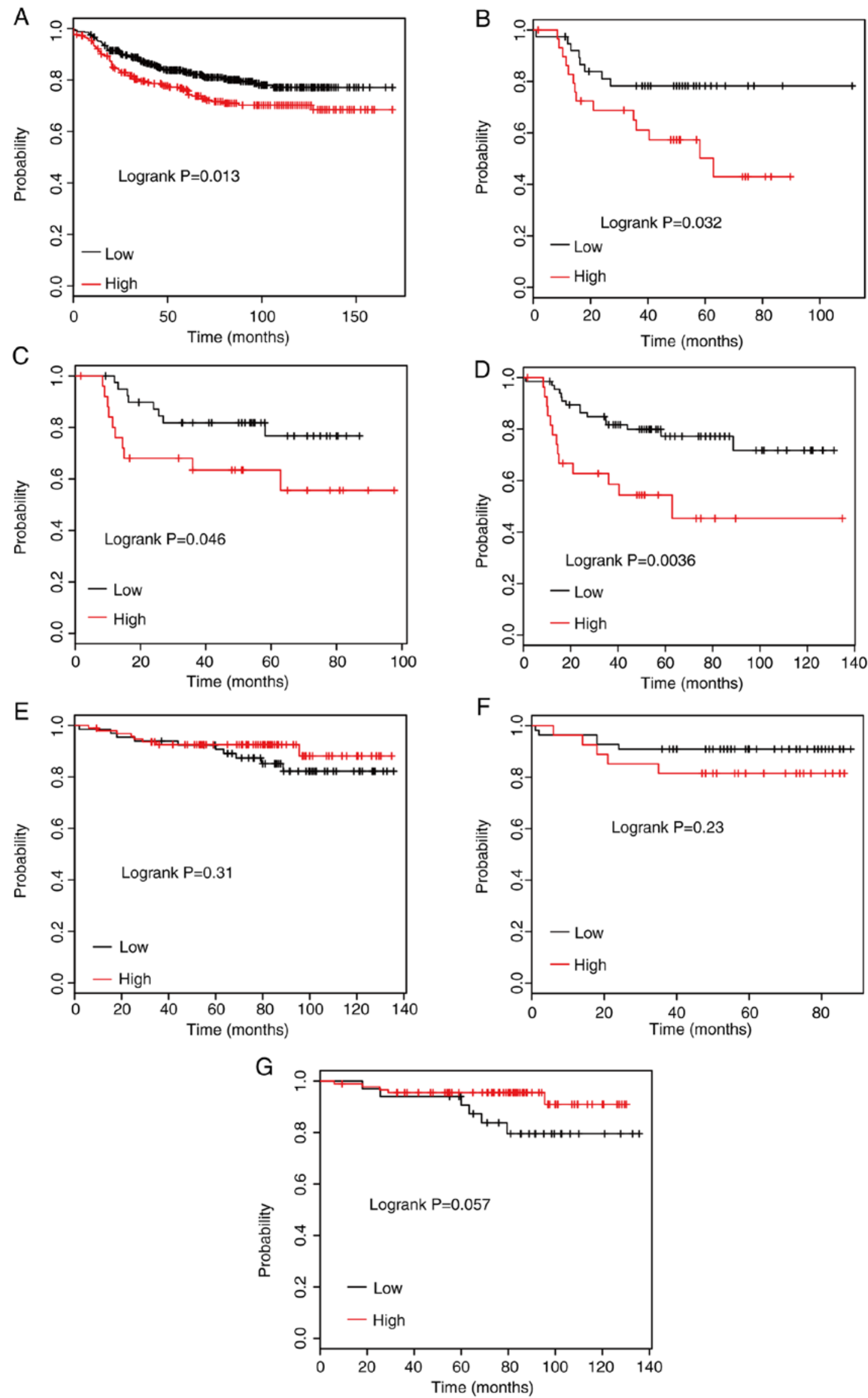

Figure 2. High STARD4 expression is associated with shorter DMFS times in BRCA. (A) Kaplan-Meier survival curve analysis with a log rank test indicated that higher expression levels of STARD4 were significantly associated with shorter DMFS time in patients with BRCA. Association between STARD4 expression and DMFS time in patients with (B) ER negative, (C) PR negative, (D) HER2 positive, (E) ER positive, (F) PR positive and (G) HER2 negative BRCA. BRCA, breast cancer; DMFS, distant metastasis-free survival; ER, estrogen receptor; PR, progesterone receptor; STARD4, steroidogenic acute regulatory protein-related lipid transfer 4. 


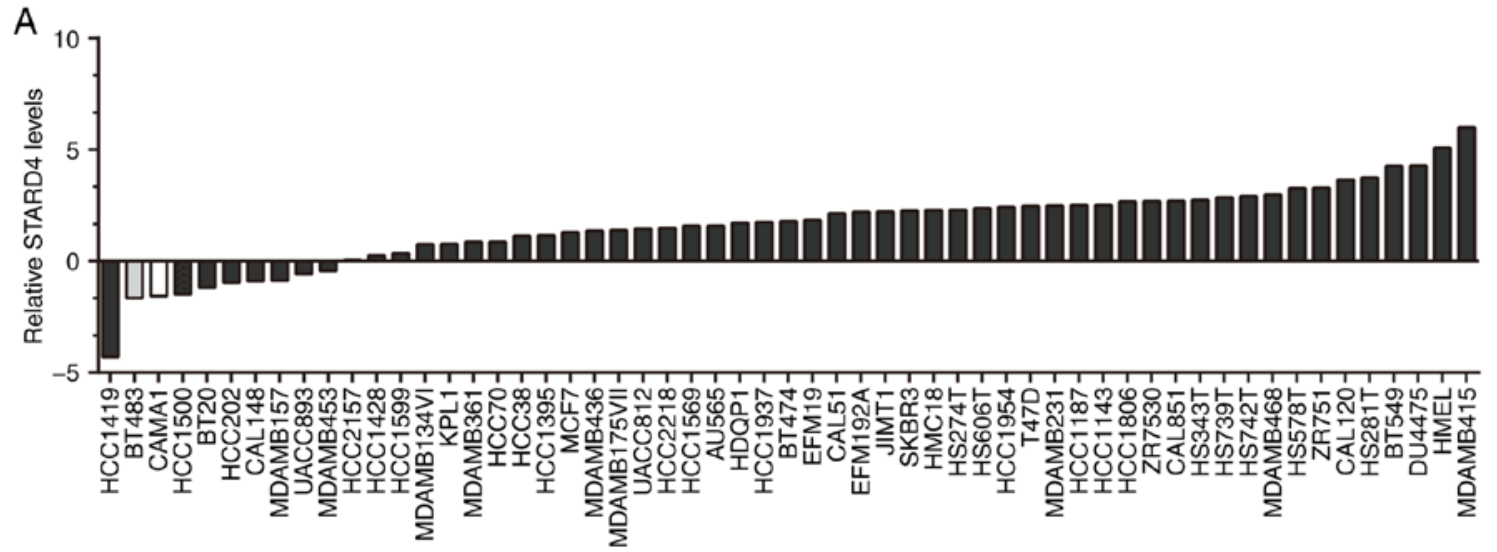

B

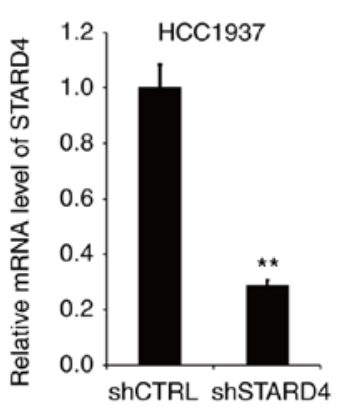

C $\quad$ HCC1937

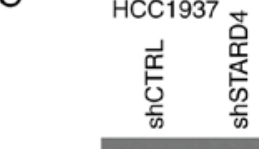

GAPDH
D

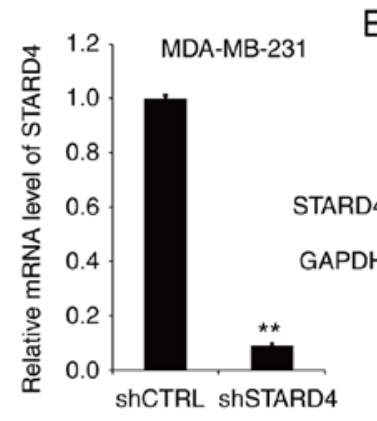

E MDA-MB-231

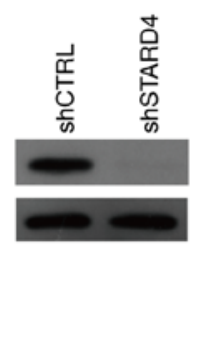

$\mathrm{F}$
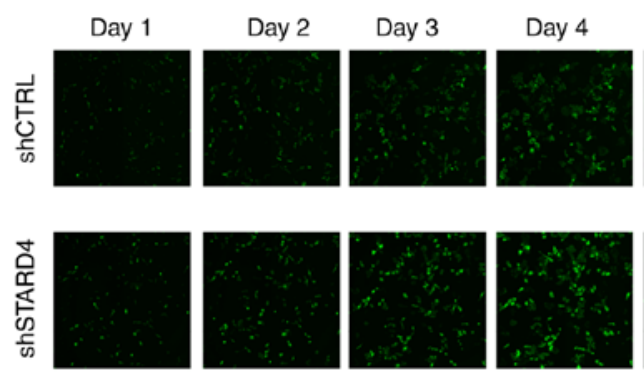

$\mathrm{H}$
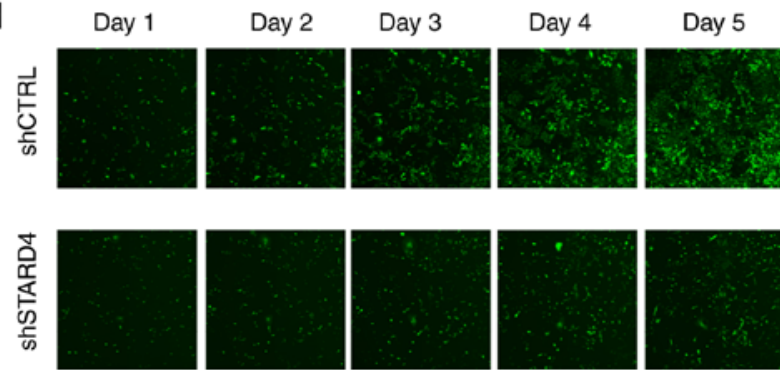

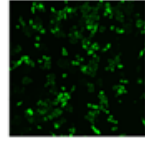

Day 5

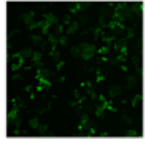

G $\quad$ HCC1937

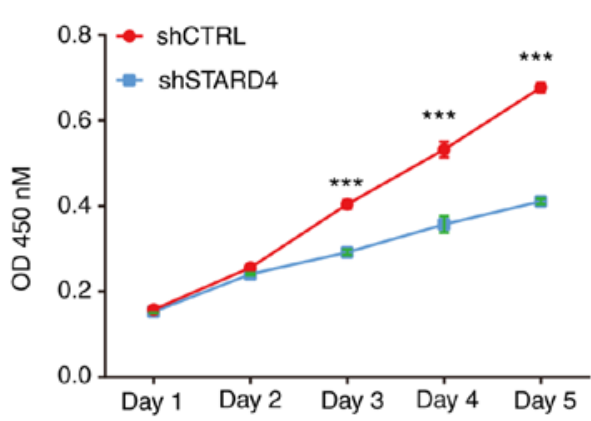

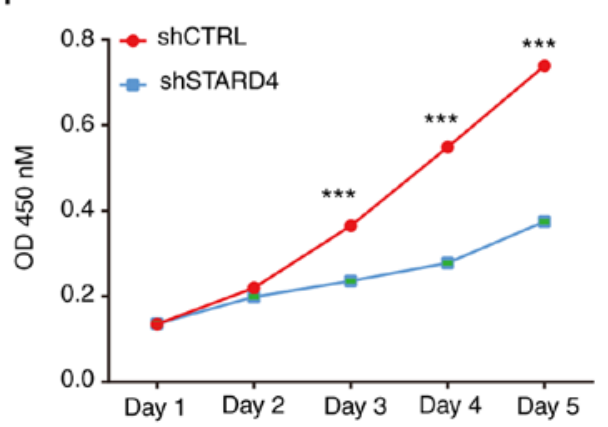

Figure 3. Knockdown of STARD4 suppresses BRCA proliferation. (A) Expression levels of STARD4 in 57 BRCA cell lines. (B) RNA and (C) protein levels of STARD4 in HCC1937 cells after transfection with shSTARD4. (D) RNA and (E) protein levels of STARD4 in MDA-MB-231 after transfection with shSTARD4. (F) Celigo cell counting and (G) CCK-8 assays demonstrated that knockdown of STARD4 suppressed HCC1937 cell proliferation. Magnification x100. (H) Celigo cell counting and (I) CCK-8 assays demonstrated that knockdown of STARD4 suppressed MDA-MB-231 cell proliferation. Magnification $x 100$. Data are presented as the mean $\pm \mathrm{SD}(\mathrm{n}=8){ }^{* * *} \mathrm{P}<0.01$ and ${ }^{* * *} \mathrm{P}<0.001$ vs. shCTRL. BRCA, breast cancer; CCK-8, Cell Counting Kit-8; CTRL, control; OD, optical density; sh, short hairpin RNA; STARD4, steroidogenic acute regulatory protein-related lipid transfer 4.

Silencing of STARD4 suppresses $G_{0} / G_{1}$ phase transition in BRCA cells. The effect of STARD4 on the cell cycle progression of BRCA cells was investigated. Flow cytometry demonstrated that knockdown of STARD4 expression in BRCA cells inhibited the cell cycle progression at the $\mathrm{G}_{0} / \mathrm{G}_{1}$ phase (Fig. 4A-D).
The proportion of cells arrested at the $\mathrm{G}_{1}$ phase was significantly higher in shSTARD4-transfected cells compared with that noted in the control cells. However, the percentage of cells arrested at the $\mathrm{S}$ phase was significantly lower in the shSTARD4-transfected cells compared with that in the control cells. 

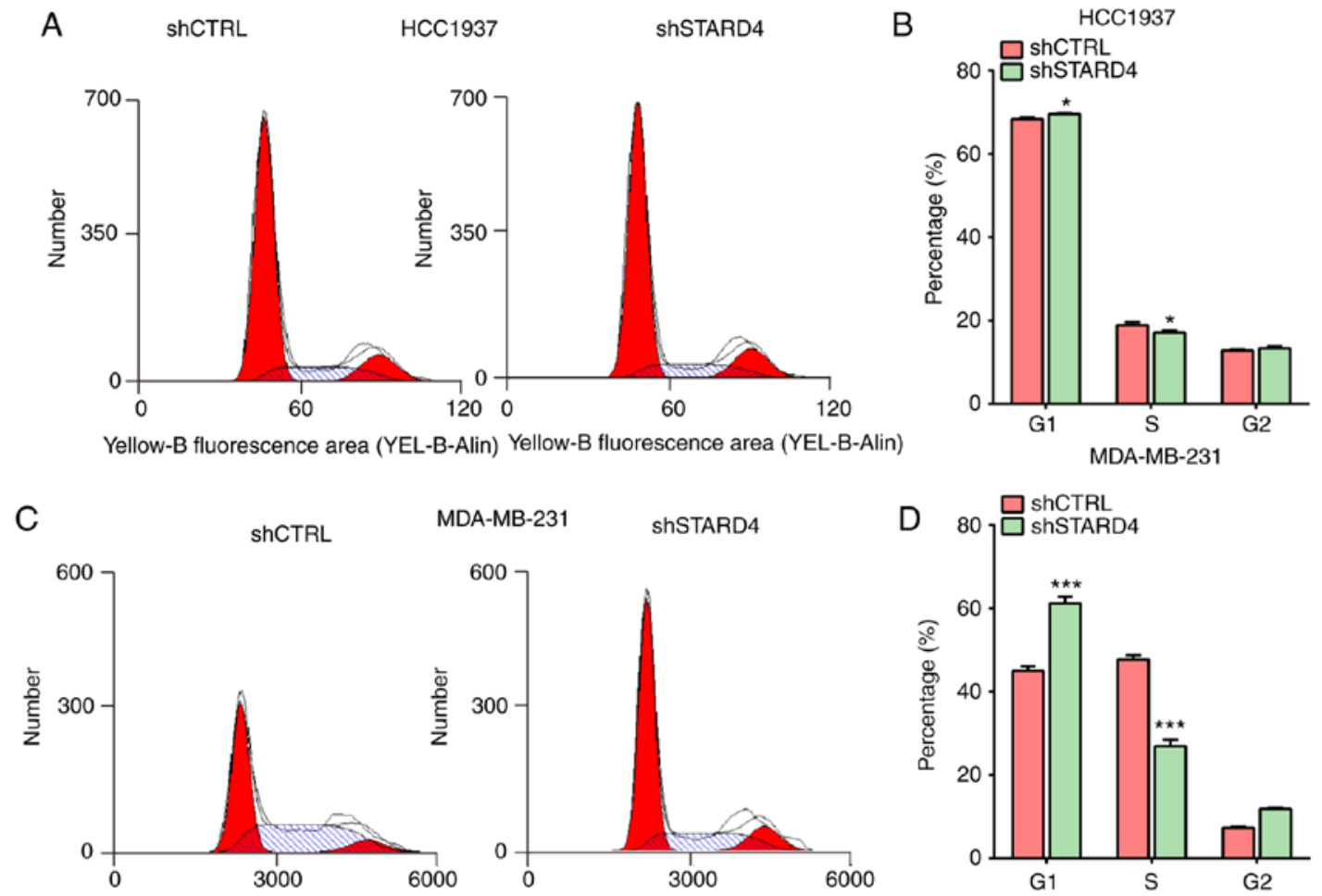

Yellow-B fluorescence area (YEL-B-Alin) Yellow-B fluorescence area (YEL-B-Alin)

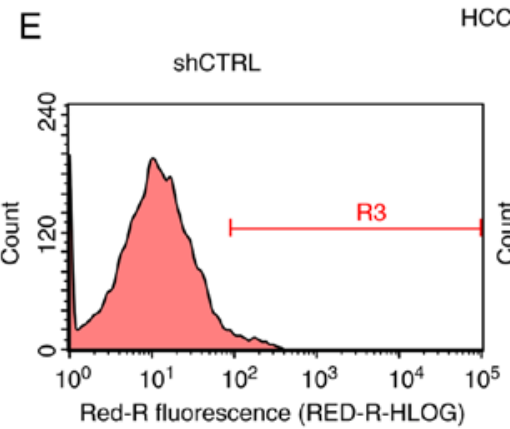

HCC1937
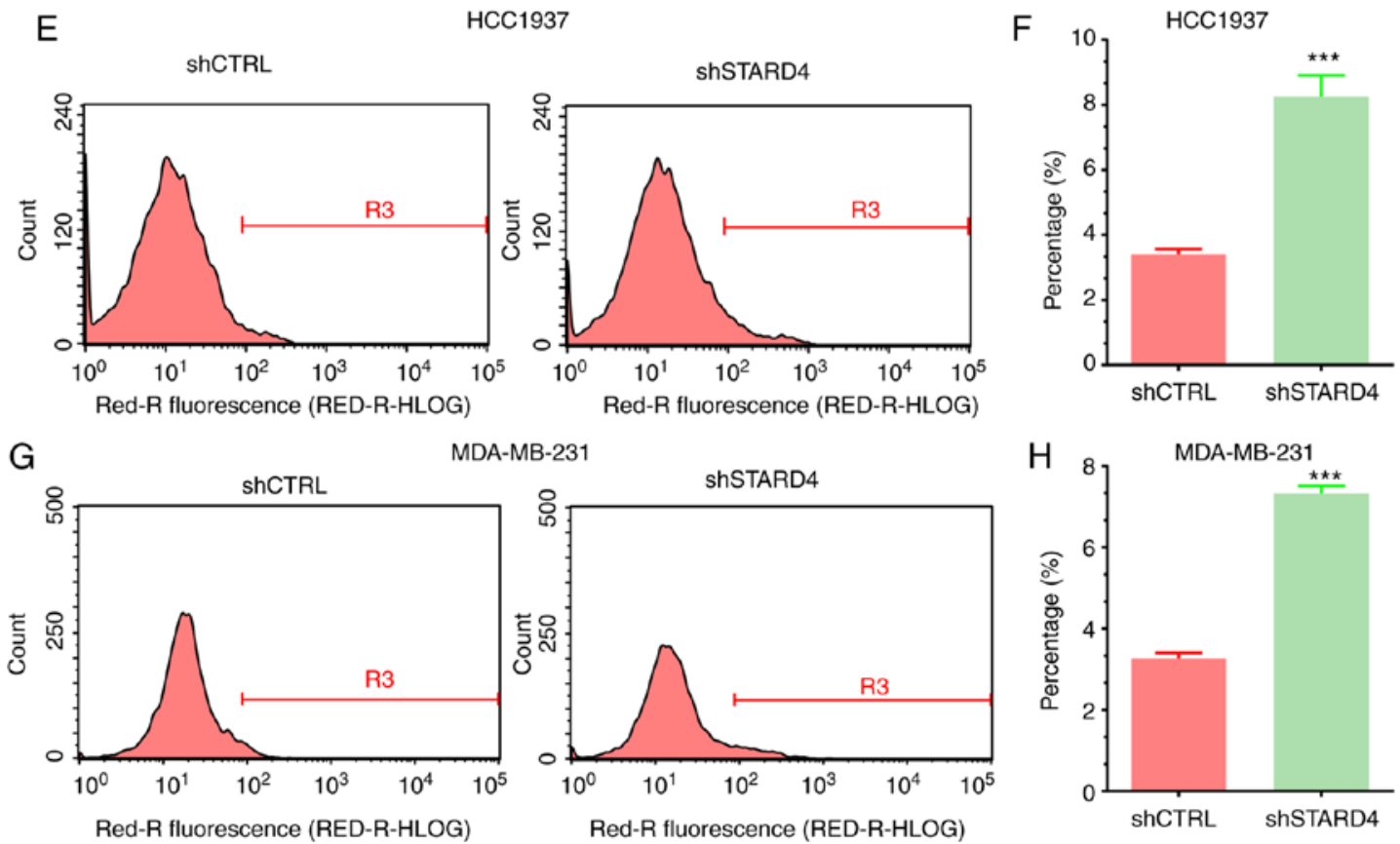

Figure 4. Knockdown of STARD4 induces breast cancer cell cycle arrest and apoptosis. (A) Knockdown of STARD4 suppressed HCC1937 cell cycle progression. (B) The percentage of cells in each phase was quantified using Prism. (C) Knockdown of STARD4 suppressed MDA-MB-231 cell cycle progression. (D) The percentage of cells in each phase was quantified using Prism. (E) Knockdown of STARD4 induced HCC1937 cell apoptosis. (F) The percentage of apoptotic cells was quantified using Prism. (G) Knockdown of STARD4 induced MDA-MB-231 cell apoptosis. (H) The percentage of apoptotic cells was quantified using Prism. Data are presented as the mean $\pm \mathrm{SD}(\mathrm{n}=3) .{ }^{*} \mathrm{P}<0.05 ;{ }^{* * *} \mathrm{P}<0.001$ vs. shCTRL. CTRL, control; sh, short hairpin RNA; STARD4, steroidogenic acute regulatory protein-related lipid transfer 4 .

Silencing of STARD4 induces apoptosis of BRCA cells. The effects of STARD4 on cell apoptosis were also investigated using flow cytometry. STARD4 knockdown induced apoptosis in BRCA cells compared with the control group. The apoptotic rates of STARD4-silenced HCC1937 and MDA-MB-231 cells were higher than those of the corresponding control groups (Fig. 4E-H). These results indicated that STARD4 may promote cell proliferation by reducing cell apoptosis.

Knockdown of STARD4 inhibits migration of BRCA cells. The ability of STARD4 to affect cell migration was examined using Transwell and wound healing assays. The results of the 

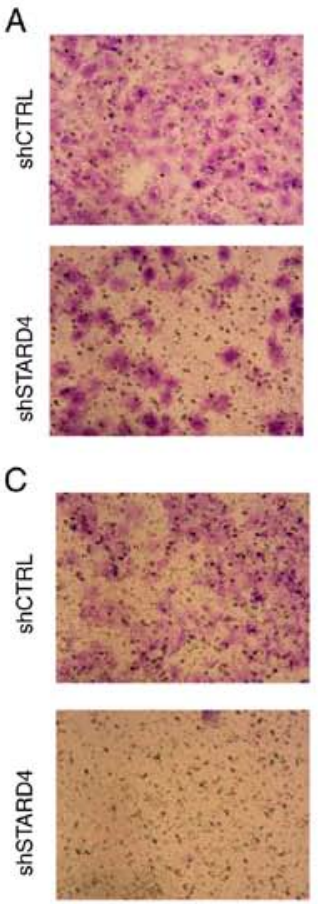

E
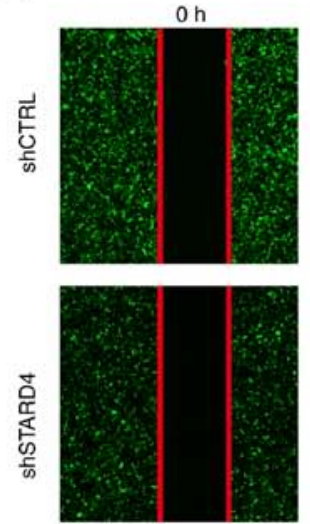

G
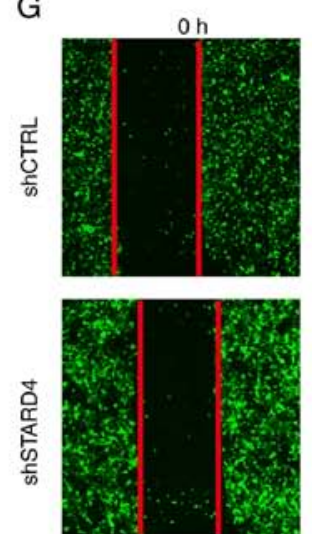

HCC1937
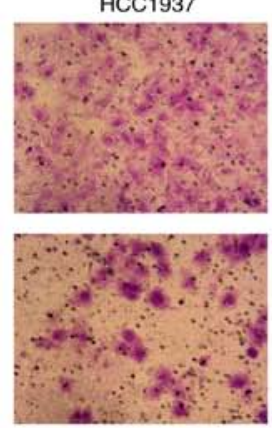

MDA-MB-231
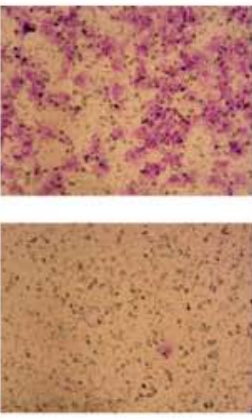

HCC1937
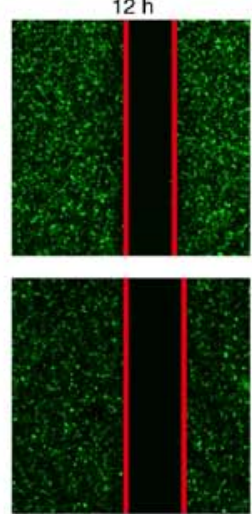

MDA-MB-231
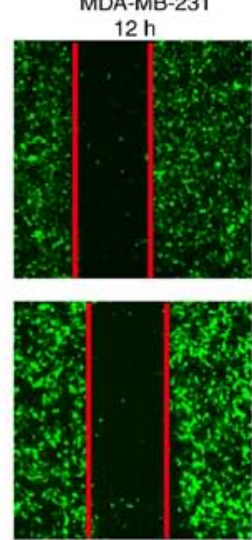
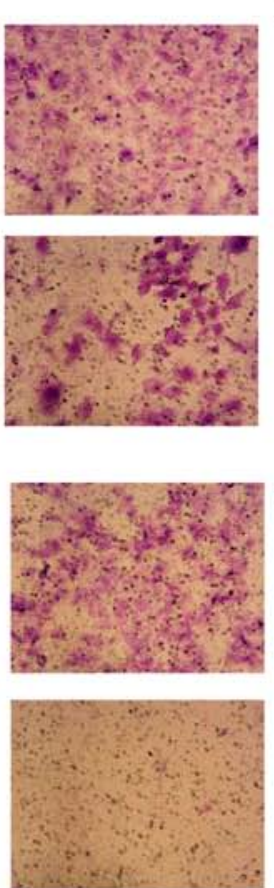

$24 \mathrm{~h}$
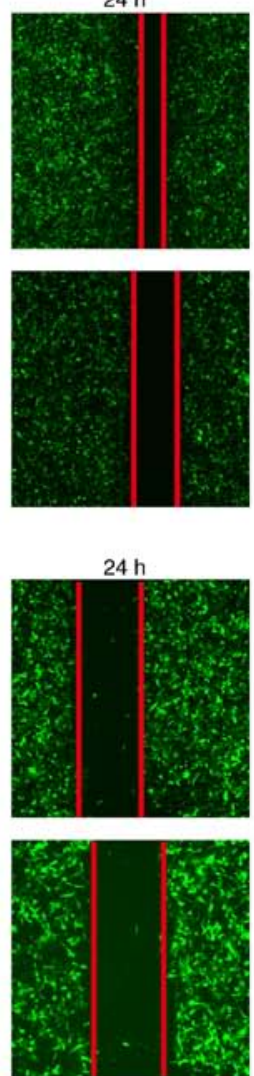

B
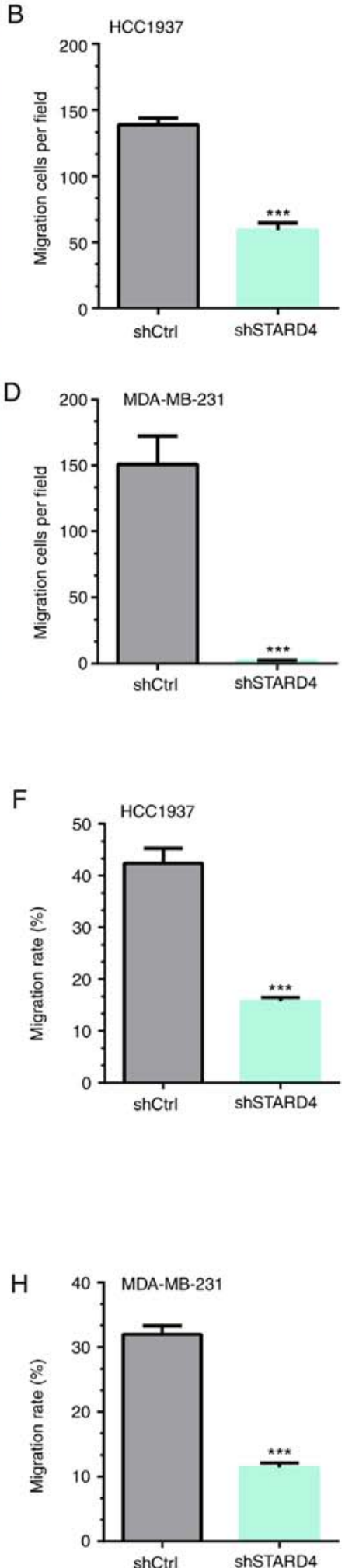

Figure 5. Knockdown of STARD4 suppresses breast cancer cell migration. (A and B) Transwell assay revealing that STARD4 knockdown significantly inhibited HCC1937 cell migration. Three replicates from an independent assay are presented. Magnification x200. (C and D) Transwell assay revealing that STARD4 knockdown significantly inhibited MDA-MB-231 cell migration. Three replicates from an independent assay are presented. Magnification x200. (E and F) Wound healing assay revealing that STARD4 knockdown significantly inhibited HCC1937 cell migration. Magnification x100. (G and H) Wound healing assay revealing that STARD4 knockdown significantly inhibited MDA-MB-231 cell migration. Magnification x100. Data are presented as the mean $\pm \mathrm{SD}(\mathrm{n}=3) .{ }^{* * * *} \mathrm{P}<0.001$. CTRL, control; sh, short hairpin RNA; STARD4, steroidogenic acute regulatory protein-related lipid transfer 4.

Transwell assay demonstrated that the migratory activity of HCC1937 and MDA-MB-231 cells was significantly attenuated following transfection with STARD4 shRNA compared with that of the negative control cells (by 59 and $99 \%$, respectively; Fig. 5A-D). Similar results were observed in the wound healing assay (Fig. 5E-H). 

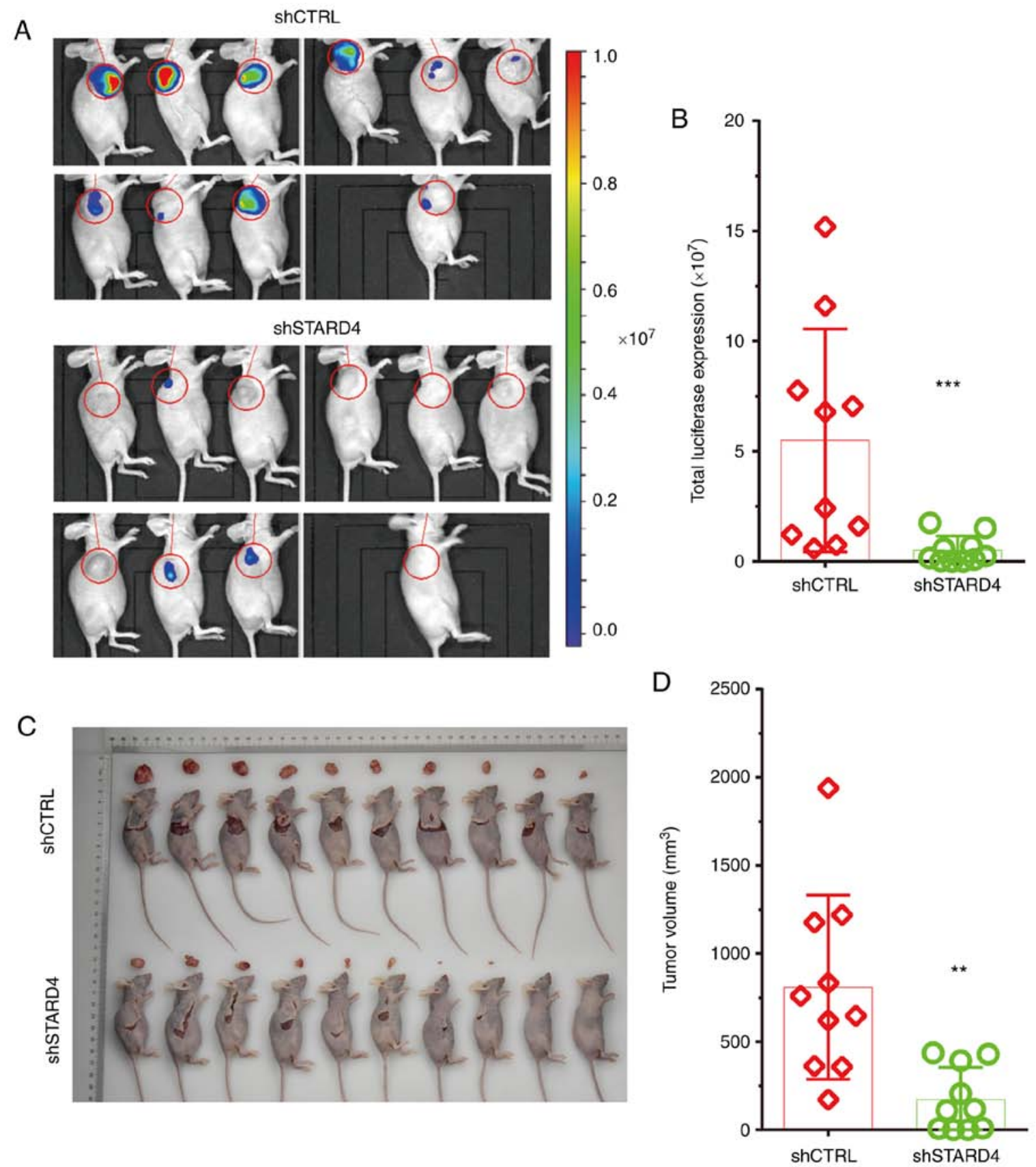

Figure 6. Knockdown of STARD4 suppresses BRCA growth in vivo. (A) STARD4 knockdown inhibited BRCA growth in vivo. (B) Luciferase activity was significantly lower in the STARD4 knockdown group compared with in the control group. (C) Images of tumors in each group. (D) Tumor volume was significantly decreased in the STARD4 knockdown group compared with in the control group. Data are presented as the mean $\pm \mathrm{SD}(\mathrm{n}=3)$. ${ }^{* *} \mathrm{P}<0.01,{ }^{* * * *} \mathrm{P}<0.001$. BRCA, breast cancer; CTRL, control; sh, short hairpin RNA; STARD4, steroidogenic acute regulatory protein-related lipid transfer 4.

Knockdown of STARD4 suppresses BRCA growth in vivo. The effects of STARD4 knockdown on tumor growth were analyzed in vivo using a nude mouse model. The luciferase-expressing MDA-MB-231 cells were constructed to implant tumors in live animals. Using an IVIS system, the data indicated that luciferase signaling in the STARD4 knockdown group was decreased compared with that in the control group (Fig. 6A and B). It was revealed that the tumor volume in the STARD4 knockdown group was lower than that in the negative control group (Fig. 6C and D).

Identification of STARD4 downstream targets in BRCA using microarray analysis. To understand the mechanisms of STARD4 in regulating BRCA progression, a gene expression microarray was used to identify targets of STARD4 in MDA-MB-231 cells. A total of 772 genes, including 350 upregulated and 422 downregulated genes, were identified as downstream targets of STARD4 in BRCA (Fig. 7A; Table SIII).

In order to validate the downstream targets of STARD4 identified by microarray analysis, the expression levels of the potential targets were detected following silencing of STARD4. A total of 10 upregulated (RPS15A, PLA2G12A, CDKN1B, ITGA5, FKBP1A, PIK3R1, HDAC6, RPSA, CDK6 and RAP1A; Fig. 7B) and 21 downregulated genes (RPS2, JMJD7.PLA2G4B, CDK1, EIF4A2, ELF1, CCNE2, RHOJ, HMOX1, PRKCE, CREB1, PLD6, PAK2, GRB2, PRKAG2, 


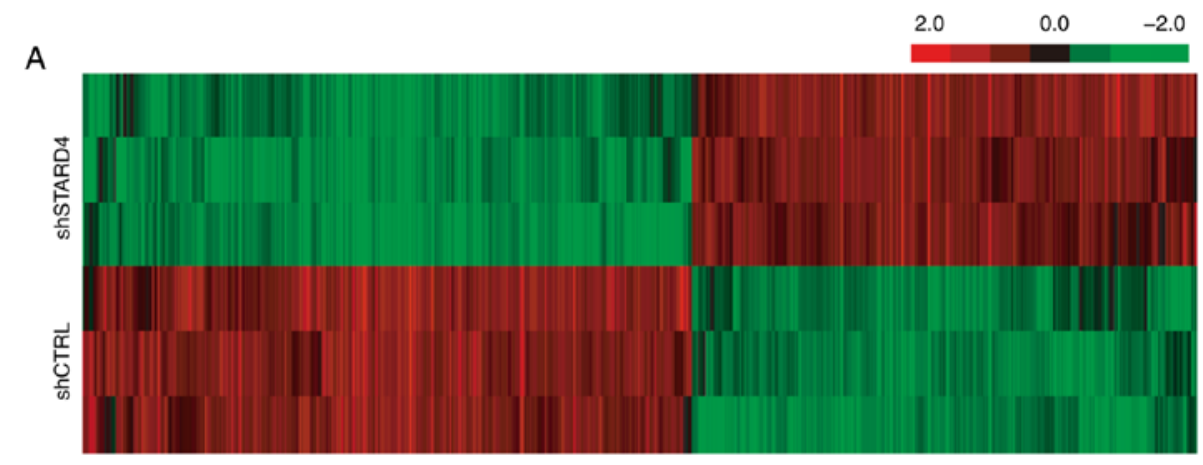

B

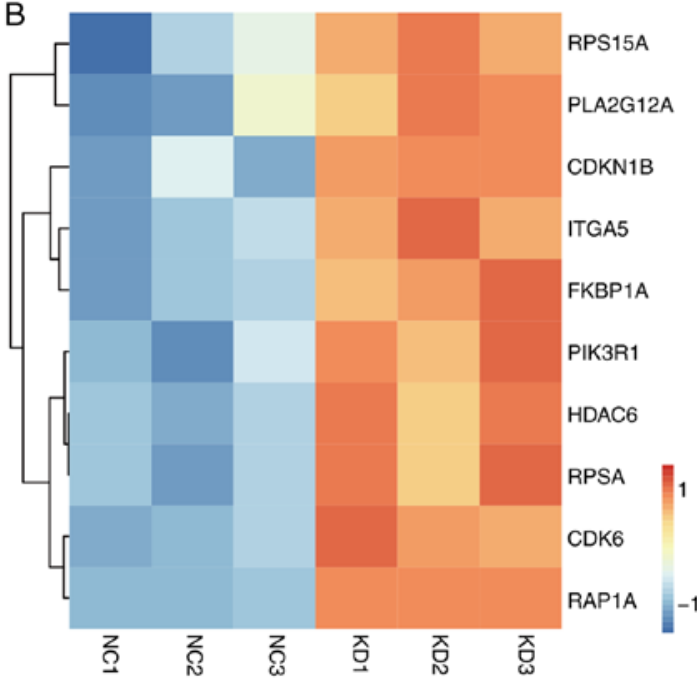

D 2.0$] \square$ shCTRL

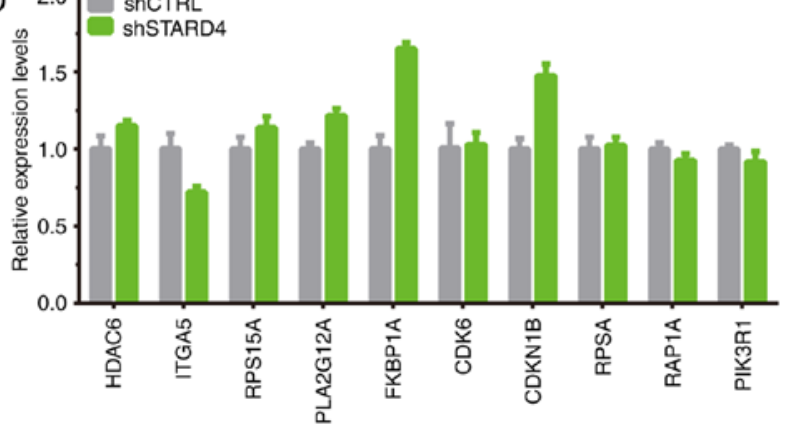

E

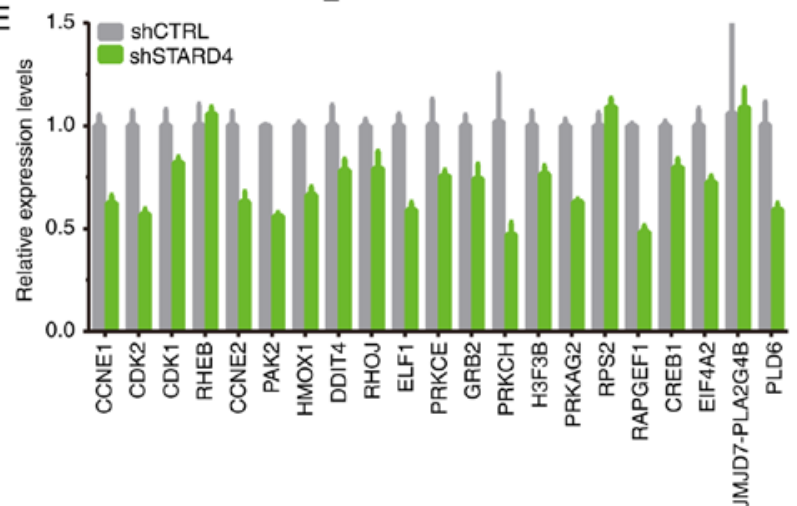

C

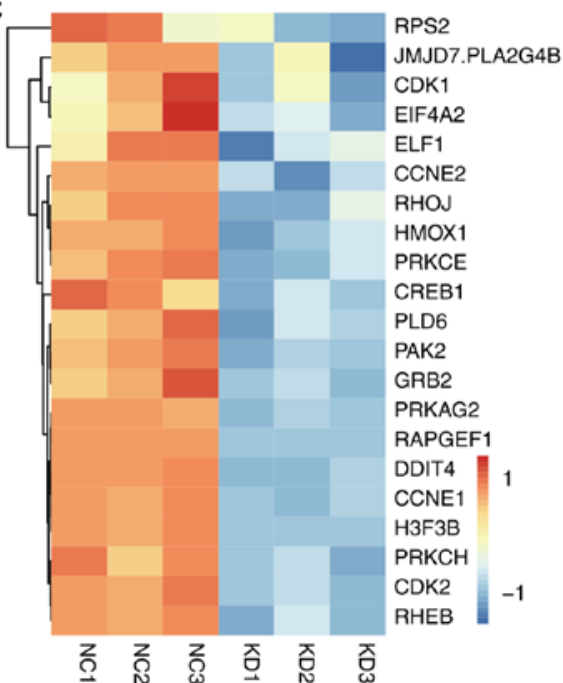

$\mathrm{F}$ ShCTRL SHSTARD4

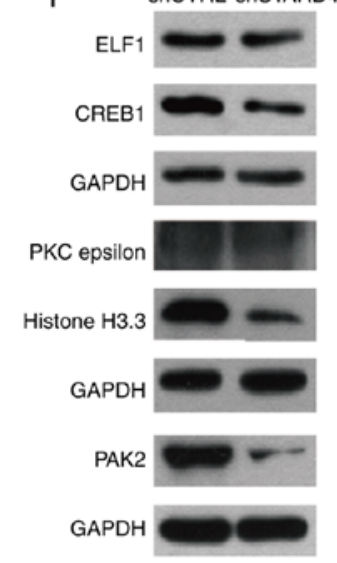

Figure 7. Identification of genes regulated by STARD4 in BRCA. (A) A heatmap presenting the differentially expressed genes following STARD4 knockdown. A total of (B) 10 upregulated and (C) 21 downregulated genes were selected for further validation. (D) Expression levels of upregulated genes after STARD4 knockdown were detected using RT-qPCR. (E) Expression levels of downregulated genes after STARD4 knockdown were detected using RT-qPCR. (F) Western blot analysis of the protein levels of STARD4 targets after STARD4 knockdown. At least three independent experiments were performed. CTRL, control; RT-qPCR, reverse transcription-quantitative PCR; sh, short hairpin RNA; STARD4, steroidogenic acute regulatory protein-related lipid transfer 4.

RAPGEF1, DDIT4, CCNE1, H3F3B, PRKCH, CDK2 and RHEB; Fig. 7C) were selected for further validation. The results indicated that knockdown of STARD4 increased the expression levels of CDKN1B and FKBP1A (Fig. 7D), but 

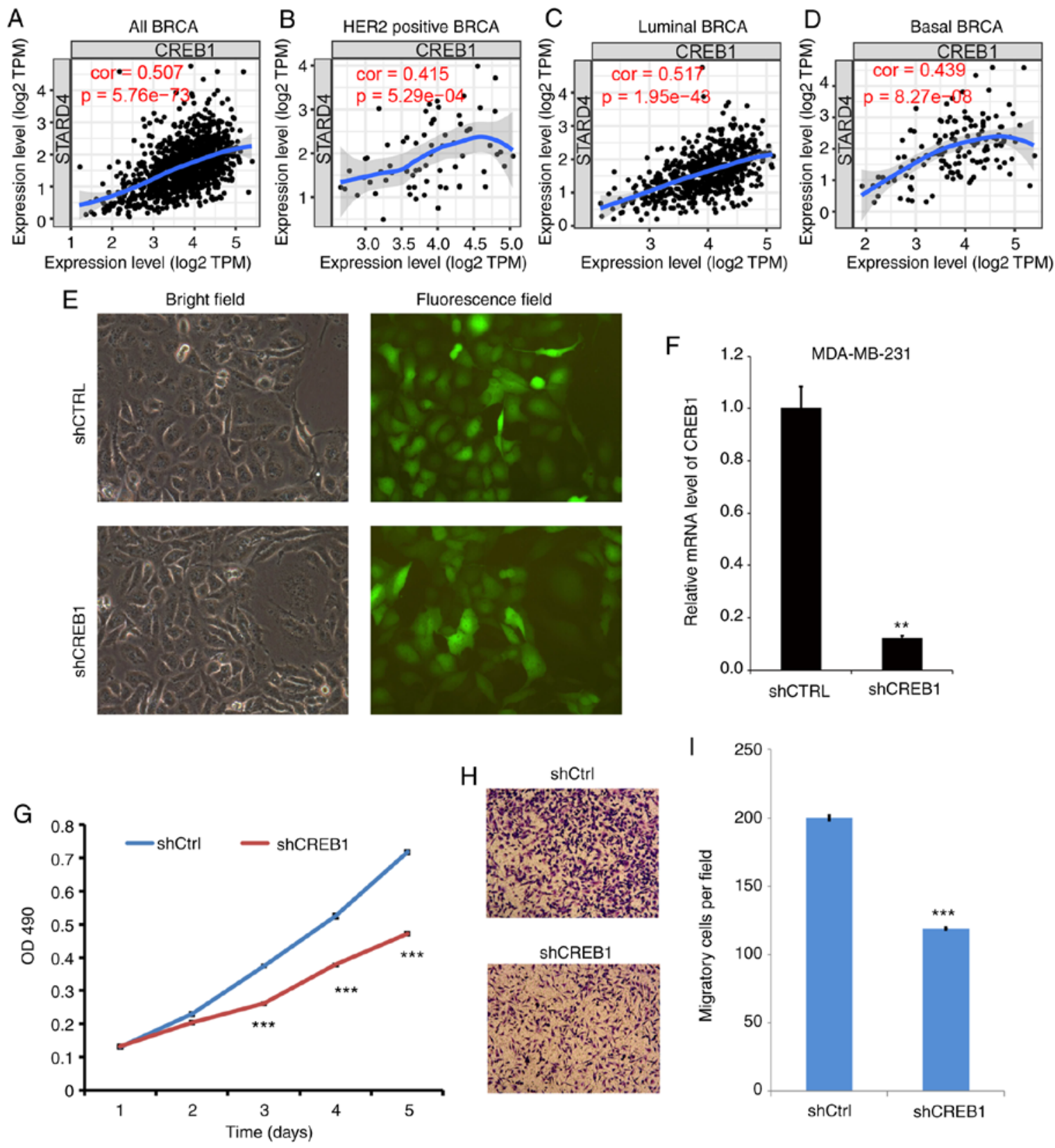

Figure 8. Knockdown of CREB1 suppresses cell proliferation and migration in BRCA. (A-D) Correlations between CREB1 and STARD4 in (A) all types of BRCA, (B) HER2-positive BRCA, (C) luminal BRCA and (D) basal BRCA were analyzed using the Tumor Immune Estimation Resource database. (E) Transfection of MDA-MB-231 cells with control vector and shCREB1. Magnification x200. (F) CREB1 expression was detected in different groups. (G) Cell Counting Kit-8 assay demonstrating that knockdown of CREB1 suppressed MDA-MB-231 cell proliferation. (H and I) Transwell assay revealing that knockdown of CREB1 suppressed MDA-MB-231 cell migration. Magnification $\mathrm{x} 100$. At least three independent experiments were performed. ${ }^{* *} \mathrm{P}<0.01$, ${ }^{* * * *} \mathrm{P}<0.001$ vs. shCTRL. BRCA, breast cancer; CREB1, cAMP responsive element binding protein 1; CTRL, control; OD, optical density; sh, short hairpin RNA; STARD4, steroidogenic acute regulatory protein-related lipid transfer 4; shCtrl, shcontrol.

decreased the expression levels of PRKCH, RAPGEF1, p21 (RAC1) activated kinase 2 (PAK2), CDK2, CREB1, E74 like ETS transcription factor 1 (ELF1), PLD6, CCNE1, CCNE2, PRKAG2 and HMOX1 (Fig. 7E). Furthermore, western blot analysis indicated that the protein expression levels of ELF1, CREB1 and PAK2 were reduced in the STARD4 knockdown group compared with those in the control group (Fig. 7F). However, the protein levels of PKC epsilon, and Histone H3.3 were not changed following STARD4 knockdown (Fig. 7F).

Knockdown of CREB1 suppresses cell proliferation and migration in BRCA. The present study focused on CREB1, which showed the most significant decreased expression following STARD4 knockdown. When analyzing the correlation between CREB1 and STARD4 using the TIMER database, a significant positive correlation between the two genes was observed in all types of BRCA (Fig. 8A), HER2 positive BRCA (Fig. 8B), luminal BRCA (Fig. 8C) and basal BRCA (Fig. 8D).

Loss-of-functions assays were used to detect the effects of CREB1 on cell proliferation and migration. The infection efficiency and knockdown efficiency are shown in Fig. 8E and F. As shown in Fig. 8G, knockdown of CREB1 significantly reduced cell proliferation in MDA-MB-231 cells compared 
with in control cells at day 3,4 and 5 . The results of the Transwell assay demonstrated that the migratory activity of MDA-MB-231 cells transfected with CREB1 shRNA was significantly attenuated compared with that of the negative control cells (Fig. 8H and I).

\section{Discussion}

The mechanisms underlying the progression of BRCA remain largely unclear $(33,34)$. In addition, the molecular functions of STARD4 in human cancers have not been fully examined. The present study indicated that the expression levels of STARD4 were upregulated in BRCA samples. Higher expression levels of STARD4 were significantly associated with shorter DMFS time in patients with ER-negative, HER2-positive and PR-negative BRCA. The results indicated that STARD4 may be associated with the regulation of BRCA progression. Additional validation demonstrated that STARD4 promoted BRCA progression by inducing cell proliferation, cell cycle progression and migration, and by suppressing apoptosis in BRCA cells. To the best of our knowledge, the present study was the first to indicate that STARD4 may function as an oncogene and promote the tumorigenesis of BRCA.

By detecting the protein levels of STARD4 in BRCA, the present study further validated the results of the public dataset analysis which suggested that STARD4 was upregulated in BRCA samples. Upregulation of this protein was noted in BRCA samples. The present study demonstrated that positive protein expression of STARD4 was associated with ER expression, whereas it was not significantly associated with PR status, HER-2 status or TNM stage. These results suggested that STARD4 may be involved in regulating the imbalance of cholesterol in patients with ER-negative BRCA, which requires further validation in future studies. ER $\alpha$ and ER $\beta$ are highly expressed in $>75 \%$ of patients with BRCA and serve a crucial role in mammary gland development (35). ER is involved in the regulation of energy metabolism, including insulin sensitivity, glucose metabolism balance and fat synthesis (36). For example, ER interacts with serine/threonine kinase 11, which negatively interferes with the phosphorylation of protein kinase AMP-activated catalytic subunit $\alpha 2$, thereby inhibiting TSC2/mTOR/p70S6K signaling (37). Notably, the present study revealed a significant negative correlation between ER expression and STARD4 levels using public databases and clinical samples. STARD4 is involved in the regulatory mechanism of intracellular cholesterol homeostasis and serves a key role in transporting $7 \alpha$-hydroperoxycholesterol $(7 \alpha-\mathrm{OOH})$ from liposomes to isolated mitochondria (38). $7 \alpha-\mathrm{OOH}$ exposure contributes to a significant reduction in 27-hydroxycholesterol (27-HC) (39). The potential roles of $27-\mathrm{HC}$ in affecting ER expression and activity have been revealed in multiple studies (40-43). Exogenous 27-HC increases ER-mediated transcription and expression of the endogenous estrogen-regulated gene trefoil factor 1 in $\mathrm{ER}^{+}$long-term estrogen deprivation (LTED) cells but not in the ER- LTED cells (40). Additionally, a previous study has demonstrated that $27-\mathrm{HC}$ exerts agonist activity on both the estrogen and liver X receptors (41-43). Despite this, the detail mechanisms remain to be investigated further. To the best of our knowledge, the present study was the first to reveal the correlation between STARD4 and ER expression in BRCA, which may be modulated by cholesterol homeostasis.

In human cells, STARD4 promotes the transport of cholesterol to the mitochondria via the bile acid synthesis pathway and leads to an increase in cholesterol metabolites (38). In addition, STARD4 can transport cholesterol to the reticular vesicles, which exhibit high activity levels of acetyl-CoAzyme A (cholesterol acyltransferases; ACAT) for esterification and storage of cholesterol (45). STARD4 is co-localized with ACAT1 in the endoplasmic (44) reticulum and serves a crucial role in the formation of lipid droplets (45). A previous study further demonstrated that only STARD4 from the STARD family of proteins could increase the activity of ACAT (14). Previous studies have reported that ACAT1 is upregulated in a series of human cancers and that it is involved in regulating cancer proliferation, invasion and glycolysis (46-48). Antalis et al (48) reported that ACAT1 could promote BRCA proliferation and metastasis. Considering the interaction between ACAT1 and STARD4, these reports indicated the potential regulatory roles of STARD4 in BRCA. The present study explored the potential functions of STARD4 in BRCA using loss-of-function assays. The data indicated that knockdown of STARD4 significantly suppressed MDA-MB-231 and HCC1937 cell proliferation, cell cycle progression and migration, whereas it promoted cell apoptosis, suggesting that this gene acted as an oncogene in BRCA.

In order to investigate the mechanisms of STARD4 underlying BRCA progression, microarray and bioinformatics analyses were performed. Several crucial regulators implicated in cancer progression were identified as STARD4-regulated genes, including ELF1, CREB1 and PAK2, which suggested that STARD4 acted as an oncogene. ELF1 is an important ETS family member and can act both as an activator and a repressor in the regulation of the transcription of various genes (49). ELF1 regulates several important factors, such as SCL, in hematopoietic stem cells (49). A limited number of studies have demonstrated that ELF1 is involved in regulating the progression of human cancer $(50,51)$. For example, ELF1 is overexpressed in acute myeloid leukemia (52). However, in prostate cancer, ELF1 has been reported as a tumor suppressor, which suppresses cancer metastasis and cellular senescence (51). CREB1 is a nuclear transcription factor which is overexpressed in multiple human cancers, including lung and colorectal cancer, glioma and BRCA (53). CREB1 can affect a series of key regulators in cancer, such as the apoptosis-associated gene $\mathrm{Bcl}-2$, the invasion-associated gene MMP9 and the cell cycle-associated genes cyclin A1, cyclinB1 and cyclin D1 (54). PAK2 is a member of the group I P21 activated kinases family of serine/threonine kinases, which are involved in modulating apoptosis $(55,56)$. Previous studies have demonstrated that PAK2 is overexpressed in different human cancer types, including ovarian (57), gastric (58) and head and neck cancer (59). The present study revealed that CREB1 was a potential target of STARD4 in patients with BRCA. Knockdown of CREB1 significantly suppressed BRCA cell proliferation and migration.

The present study had several limitations. First, the roles of STARD4 in HER2-positive BRCA require further investigation. More in vivo and in vitro assays should be performed to explore the potential roles of STARD4 in HER2-positive 
cells. Second, the mechanisms of STARD4 in the regulation of CREB1 expression should be explored further. Third, STARD4 was only significantly associated with the survival time in patients with BRCA in ER negative, HER2 positive and PR negative groups. These results suggested that STARD4 may have different roles in different types of BRCA. The present study mainly explored the potential roles of STARD4 in TNBC. In a future study, more clinical samples will be collected to confirm this finding and explore the roles in all type of BRCA.

In conclusion, the results of the present study indicated that the expression levels of STARD4 were increased in BRCA, and that STARD4 expression was associated with BRCA malignancy. Furthermore, the present study demonstrated that STARD4 acted as an oncogene in BRCA. These results suggest that STARD4 can be used as a potential promising biomarker and provide a novel therapeutic target for BRCA treatment.

\section{Acknowledgements}

Not applicable.

\section{Funding}

The present study was supported by grants from The National Natural Science Foundation of China (grant no. 81572612), The National Key Clinical Specialist Construction Programs of China (grant no.2014kll), and the Research Innovation Program for Graduate Students of Central South University (grant nos. 2018zzts912;502211901).

\section{Availability of data and materials}

The datasets used and/or analyzed during the current study are available from the corresponding author on reasonable request.

\section{Authors' contributions}

$\mathrm{MZ}$ and WBZ conceived the experiments and drafted the manuscript. MZ, ZX, FW and RS conducted the experiments. LL, JC, BAL, JH and LQS analyzed and interpreted the data. All authors agree to be accountable for all aspects of the research in ensuring that the accuracy or integrity of any part of the work are appropriately investigated and resolved. All authors read and approved the final manuscript.

\section{Ethics approval and consent to participate}

The present study was approved by the Ethics Committees of Central South University. Informed consent was obtained from all individual participants in the study. All animal handling and experimental procedures were approved by the Animal Ethics Committees of Central South University and were in accordance with the guidelines of the China Council of Animal Care.

\section{Patient consent for publication}

Not applicable.

\section{Competing interests}

The authors declare that they have no competing interests.

\section{References}

1. Wagner J, Rapsomaniki MA, Chevrier S, Anzeneder T, Langwieder C, Dykgers A, Rees M, Ramaswamy A, Muenst S, Soysal SD, et al: A single-cell atlas of the tumor and immune ecosystem of human breast cancer. Cell 177: 1330-1345 e1318, 2019.

2. Ciriello G, Gatza ML, Beck AH, Wilkerson MD, Rhie SK, Pastore A, Zhang H, McLellan M, Yau C, Kandoth C, et al: Comprehensive molecular portraits of invasive lobular breast cancer. Cell 163: 506-519, 2015.

3. Jung SY, Rosenzweig M, Sereika SM, Linkov F, Brufsky A and Weissfeld JL: Factors associated with mortality after breast cancer metastasis. Cancer Causes Control 23: 103-112, 2012.

4. Li XH, Song JW, Liu JL, Wu S, Wang Ls, Gong Ly and Lin X: Serine-Arginine protein kinase 1 is associated with breast cancer progression and poor patient survival. Med Oncol 31: 83, 2014.

5. Bray F, Ferlay J, Soerjomataram I, Siegel RL, Torre LA and Jemal A: Global cancer statistics 2018: GLOBOCAN estimates of incidence and mortality worldwide for 36 cancers in 185 countries. CA Cancer J Clin 68: 394-424, 2018.

6. Zhu J and Thompson CB: Metabolic regulation of cell growth and proliferation. Nat Rev Mol Cell Biol 20: 436-450, 2019.

7. Kamphorst JJ and Gottlieb E: Cancer metabolism: Friendly neighbours feed tumour cells. Nature 536: 401-402, 2016.

8. Wagner EF and Petruzzelli M: Cancer metabolism: A waste of insulin interference. Nature 521: 430-431, 2015.

9. Tasselli L and Chua KF: Cancer: Metabolism in 'the driver's seat'. Nature 492: 362-363, 2012.

10. Cao Y: Adipocyte and lipid metabolism in cancer drug resistance. J Clin Invest 129: 3006-3017, 2019.

11. Chang IY, Ohn T, Ko GS, Yoon Y, Kim JW and Yoon SP: Immunolocalization of steroidogenic acute regulatory protein-related lipid transfer (START) domain-containing proteins in the developing cerebellum of normal and hypothyroid rats. J Chem Neuroanat 43: 28-33, 2012.

12. Ishikawa T, Hwang K, Lazzarino D and Morris PL: Sertoli cell expression of steroidogenic acute regulatory protein-related lipid transfer 1 and 5 domain-containing proteins and sterol regulatory element binding protein-1 are interleukin-1beta regulated by activation of $\mathrm{c}$-jun $\mathrm{n}$-terminal kinase and cyclooxygenase- 2 and cytokine induction. Endocrinology 146: 5100-5111, 2005.

13. Clark BJ: The mammalian START domain protein family in lipid transport in health and disease. J Endocrinol 212: 257-275, 2012.

14. Soccio RE, Adams RM, Romanowski MJ, Sehayek E, Burley SK and Breslow JL: The cholesterol-regulated starD4 gene encodes a StAR-related lipid transfer protein with two closely related homologues, starD5 and starD6. Proc Natl Acad Sci USA 99: 6943-6948, 2002.

15. Alpy F and Tomasetto C: Give lipids a START: The StAR-related lipid transfer (START) domain in mammals. J Cell Sci 118: 2791-2801, 2005.

16. Calderon-Dominguez M, Gil G, Medina MA, Pandak WM and Rodríguez-Agudo D: The starD4 subfamily of steroidogenic acute regulatory-related lipid transfer (START) domain proteins: New players in cholesterol metabolism. Int J Biochem Cell Biol 49: 64-68, 2014.

17. Riegelhaupt JJ, Waase MP, Garbarino J, Cruz DE and Breslow JL: Targeted disruption of steroidogenic acute regulatory protein $\mathrm{D} 4$ leads to modest weight reduction and minor alterations in lipid metabolism. J Lipid Res 51: 1134-1143, 2010.

18. Rodriguez-Agudo D, Ren S, Wong E, Marques D, Redford K, Gil G, Hylemon P and Pandak WM: Intracellular cholesterol transporter starD4 binds free cholesterol and increases cholesteryl ester formation. J Lipid Res 49: 1409-1419, 2008.

19. Garbarino J, Pan M, Chin HF, Lund FW, Maxfield FR and Breslow JL: STARD4 knockdown in hepG2 cells disrupts cholesterol trafficking associated with the plasma membrane, ER, and ERC. J Lipid Res 53: 2716-2725, 2012.

20. Bouhaddou M, DiStefano MS, Riesel EA, Carrasco E, Holzapfel HY, Jones DC, Smith GR, Stern AD, Somani SS, Thompson TV and Birtwistle MR: Drug response consistency in CCLE and CGP. Nature 540: E9-E10, 2016. 
21. Dey-Rao R, Smith JR, Chow S and Sinha AA: Differential gene expression analysis in CCLE lesions provides new insights regarding the genetics basis of skin vs. systemic disease. Genomics 104: 144-155, 2014.

22. Li T, Fan J, Wang B, Traugh N, Chen Q, Liu JS, Li B and Liu XS: TIMER: A web server for comprehensive analysis of tumor-infiltrating immune cells. Cancer Res 77: e108-e110, 2017.

23. Gyorffy B, Lánczky A and Szállási Z: Implementing an online tool for genome-wide validation of survival-associated biomarkers in ovarian-cancer using microarray data from 1287 patients. Endocr Relat Cancer 19: 197-208, 2012.

24. Li K, Ma YB, Zhang Z, Tian YH, Xu XL, He YQ, Xu L, Gao Y, Pan WT and Song WJ: Upregulated IQUB promotes cell proliferation and migration via activating Akt/GSK3beta/beta-catenin signaling pathway in breast cancer. Cancer Med 7: 3875-3888, 2018

25. Hammond ME, Hayes DF, Dowsett M, Allred DC, Hagerty KL, Badve S, FitzgibbonsPL, Francis G, Goldstein NS, Hayes M, et al: American society of clinical oncology/college of american pathologists guideline recommendations for immunohistochemical testing of estrogen and progesterone receptors in breast cancer. J Clin Oncol 28: 2784-2795, 2010.

26. Wolff AC, Hammond ME, Hicks DG, Dowsett M, McShane LM, Allison KH, Allred DC, Bartlett JM, Bilous M, Fitzgibbons P, et al: Recommendations for human epidermal growth factor receptor 2 testing in breast cancer: American society of clinical oncology/college of American pathologists clinical practice guideline update. J Clin Oncol 31: 3997-4013, 2013.

27. Dowsett M, Nielsen TO, A'Hern R, Bartlett J, Coombes RC, Cuzick J, Ellis M, Henry NL, Hugh JC, Lively T, et al: Assessment of Ki67 in breast cancer: Recommendations from the international Ki67 in breast cancer working group. J Natl Cancer Inst 103: 1656-1664, 2011.

28. Yang F, Liu H, Zhao J, Ma X and Qi W: POLR1B is upregulated and promotes cell proliferation in non-small cell lung cancer. Oncol Lett 19: 671-680, 2020.

29. Wan X, Kong Z, Chu K, Yi C, Hu J, Qin R, Zhao C, Fu F, $\mathrm{Wu} \mathrm{H}, \mathrm{Li}$ Y and Huang Y: Co-Expression analysis revealed PTCH1-3'UTR promoted cell migration and invasion by activating miR-101-3p/SLC39A6 axis in non-small cell lung cancer: Implicating the novel function of PTCH1. Oncotarget 9 : 4798-4813, 2018

30. Cai Z, Sanchez A, Shi Z, Zhang T, Liu M and Zhang D: Activation of toll-like receptor 5 on breast cancer cells by flagellin suppresses cell proliferation and tumor growth. Cancer Res 71: 2466-2475, 2011.

31. Livak KJ and Schmittgen TD: Analysis of relative gene expression data using real-time quantitative PCR and the 2(-Delta Delta C(T)) method. Methods 25: 402-408, 2001.

32. Wu L, Wei Y, Zhou WB, Zhang YS, Chen QH, Liu MX, Zhu ZP, Zhou J, Yang LH, Wang HM, et al: Gene expression alterations of human liver cancer cells following borax exposure. Oncol Rep 42: 115-130, 2019.

33. Wang Z, Chen J, Zhong MZ, Huang J, Hu YP, Feng DY, Zhou ZJ, Luo X, Liu ZQ, Jiang WZ and Zhou WB: Overexpression of ANLN contributed to poor prognosis of anthracycline-based chemotherapy in breast cancer patients. Cancer Chemother Pharmacol 79: 535-543, 2017.

34. Zhou W, Wang Z, Shen N, Pi W, Jiang W, Huang J, Hu Y, Li X and Sun L: Knockdown of ANLN by lentivirus inhibits cell growth and migration in human breast cancer. Mol Cell Biochem 398 : $11-19,2015$

35. Zhou W, Guan X, Wang L, Liao Y and Huang J: P12(CDK2-AP1) inhibits breast cancer cell proliferation and in vivo tumor growth. J Cancer Res Clin Oncol 138: 2085-2093, 2012.

36. Gandhi N and Das GM: Metabolic reprogramming in breast cancer and its therapeutic implications. Cells 26: 89,019.

37. Davis KE, Neinast MD, Sun K, Skiles WM, Bills JD, Zehr JA Zeve D, Hahner LD, Cox DW, Gent LM, et al: The sexually dimorphic role of adipose and adipocyte estrogen receptors in modulating adipose tissue expansion, inflammation, and fibrosis Mol Metab 2: 227-242, 2013.

38. Korytowski W, Rodriguez-Agudo D, Pilat A and Girotti AW: StarD4-Mediated translocation of 7-hydroperoxycholesterol to isolated mitochondria: Deleterious effects and implications for steroidogenesis under oxidative stress conditions. Biochem Biophys Res Commun 392: 58-62, 2010.

39. Korytowski W, Wawak K, Pabisz P, Schmitt JC, Chadwick AC, Sahoo D and Girotti AW: Impairment of macrophage cholesterol efflux by cholesterol hydroperoxide trafficking: Implications for atherogenesis under oxidative stress. Arterioscler Thromb Vasc Biol 35: 2104-2113, 2015.
40. Simigdala N, Gao Q, Pancholi S, Roberg-Larsen H, Zvelebil M Ribas R, Folkerd E, Thompson A, Bhamra A, Dowsett M and Martin LA: Cholesterol biosynthesis pathway as a novel mechanism of resistance to estrogen deprivation in estrogen receptor-positive breast cancer. Breast Cancer Res 18: 58, 2016.

41. Munir MT, Ponce C, Powell CA, Tarafdar K, Yanagita T, Choudhury M, Gollahon LS and Rahman SM: The contribution of cholesterol and epigenetic changes to the pathophysiology of breast cancer. J Steroid Biochem Mol Biol 183: 1-9, 2018.

42. He S and Nelson ER: 27-Hydroxycholesterol, an endogenous selective estrogen receptor modulator. Maturitas 104: 29-35, 2017.

43. McDonnell DP, Chang CY and Nelson ER: The estrogen receptor as a mediator of the pathological actions of cholesterol in breast cancer. Climacteric 17: 60-65, 2014.

44. Iaea DB, Dikiy I, Kiburu I, Eliezer D and Maxfield FR: STARD4 membrane interactions and sterol binding. Biochemistry 54: 4623-4636, 2015.

45. Rodriguez-Agudo D, Calderon-Dominguez M, Ren S, Marques D, Redford K, Medina-Torres MA, Hylemon P, Gil G and Pandak WM: Subcellular localization and regulation of starD4 protein in macrophages and fibroblasts. Biochim Biophys Acta 1811: 597-606, 2011

46. Garcia-Bermudez J and Birsoy K: Drugging ACAT1 for cancer therapy. Mol Cell 64: 856-857, 2016.

47. Saraon P, Trudel D, Kron K, Dmitromanolakis A, Trachtenberg J, Bapat B, van der Kwast T, Jarvi KA and Diamandis EP: Evaluation and prognostic significance of ACAT1 as a marker of prostate cancer progression. Prostate 74: 372-380, 2014

48. Antalis CJ, Arnold T, Rasool T, Lee B, Buhman KK and Siddiqui RA: High ACAT1 expression in estrogen receptor negative basal-like breast cancer cells is associated with LDL-induced proliferation. Breast Cancer Res Treat 122: 661-670, 2010.

49. Oikawa T and Yamada T: Molecular biology of the ets family of transcription factors. Gene 303: 11-34, 2003.

50. Xiao XH and He SY: ELF1 activated long non-coding RNA CASC2 inhibits cisplatin resistance of non-small cell lung cancer via the miR-18a/IRF-2 signaling pathway. Eur Rev Med Pharmacol Sci 24: 3130-3142, 2020.

51. Budka JA, Ferris MW, Capone MJ and Hollenhorst PC: Common ELF1 deletion in prostate cancer bolsters oncogenic ETS function, inhibits senescence and promotes docetaxel resistance. Genes Cancer 9: 198-214, 2018.

52. Fukushima T, Miyazaki Y, Tsushima H, Tsutsumi C, Taguchi J, Yoshida S, Kuriyama K, Scadden D, Nimer S and Tomonaga M: The level of MEF but not ELF-1 correlates with FAB subtype of acute myeloid leukemia and is low in good prognosis cases. Leukemia Res 27: 387-392, 2003.

53. Rao M, Zhu Y, Cong X and Li Q: Knockdown of CREB1 inhibits tumor growth of human gastric cancer in vitro and in vivo. Oncol Rep 37: 3361-3368, 2017.

54. Sakamoto KM and Frank DA: CREB in the pathophysiology of cancer: Implications for targeting transcription factors for cancer therapy. Clin Cancer Res 15: 2583-2587, 2009.

55. Shao Y, Qi Y, Huang Y, Liu Z, Ma Y, Guo X, Jiang S, Sun Z and Ruan Q: Human cytomegalovirus miR-US4-5p promotes apoptosis via downregulation of p21-activated kinase 2 in cultured cells. Mol Med Rep 16: 4171-4178, 2017.

56. Eron SJ, Raghupathi K and Hardy JA: Dual site phosphorylation of caspase-7 by PAK2 blocks apoptotic activity by two distinct mechanisms. Structure 25: 27-39, 2017.

57. Flate E and Stalvey JR: Motility of select ovarian cancer cell lines: Effect of extra-cellular matrix proteins and the involvement of PAK2. Int J Oncol 45: 1401-1411, 2014.

58. Gao C, Ma T, Pang L and Xie R: Activation of P21-activated protein kinase 2 is an independent prognostic predictor for patients with gastric cancer. Diagn Pathol 9: 55, 2014

59. Park J, Kim JM, Park JK, Huang S, Kwak SY, Ryu KA, Kong G, Park J and Koo BS: Association of p21-activated kinase-1 activity with aggressive tumor behavior and poor prognosis of head and neck cancer. Head Neck 37: 953-963, 2015.

This work is licensed under a Creative Commons Attribution-NonCommercial-NoDerivatives 4.0 International (CC BY-NC-ND 4.0) License. 